\title{
الوحي والعقل
}

\section{بحث في إشكالية تعارض العقل والنقل}

\section{لؤي صافي}

العقل في مواجهة الوحي قضية شغلت منذ القديم، وما زالت تشغل علماء الأمة ومفكريها. واتخذت

القضية أشكالاً ختخلفة وانتحلت أسماء متغايرة، فهي قضية السَمْع والعقل، أو النقل والعقل، أو الخبر والعقل. وهي قضية الرأي مقابل البيان، والنظر مقابل العرفان. وانقسم العلماء في تعريفهم للعلاقة بين الوحي والعقل في دائرة الفقه إلى مذاهب كالأحناف والشافعية والمالكية والحنابلة والظاهرية، وفي دائرة التوجه العقدي إلى فرق كالخوارج والشيعة والسنة، وفي دائرة التصور إلى مدارس كالحشوية والمعتزلة والأشاعرة والفلاسفة. ومع اجتياح المد الثقافي والحضاري الغربي معاقل الفكر الإسلامي التاريخية ازدادت علاقة الوحي بالعقل تعقيداً، وانضافت إلى المشكلات التي أدت إلى الخلافات المذكورة آنفاً -وهي في حقيقتها مشكلات ارتباطمشكلة أكثر خطراً وأعظم أثراً، مشكلة انفكاك الوحي والعقل في الخبرة التاريخية الغربية.

إن المتأمل في الخريطة الفكرية للعالم الإسلامي اليوم يلحظ أن الانقسامات الفكرية الكبرى يككن ردها إلى قضية العلاقة بين الوحي والعقل. بل يمكننا القول إنَّ الانقسامات الفكرية تعكس الإشكاليتين الرئيسيتين التي تواجهان العقل في علاقته بالوحي: إشكالية التعارض وإشكالية الكفاية. فانقسام مثقفي الأمة ومفكريها بين الاتحاهين الإسلامي والعلماني يعود من حيث دواعيه النظرية إلى إثكالية الكفاية المتمثلة في تشديد الفئة السابقة على مصدرية الوحي المعرفية ومرجعيته القيمية وإصرار الفئة اللاحقة على كفاية العقل في توليد التصورات وإنشاء القِيَم وهداية الفرد والمجتمع. كما يمكن إعادة انقسام الإسلاميين بين الاتجاهين الإحيائي والإصلاحي إلى إشكالية التعارض المتمثلة في رفض الإحيائين كل اجتهاد يخالف في منهجه أو مضمونه التفسيرات التراثية لنصوص الوحي، وتأكيد الإصلاحيين ضرورة إعمال النظر من جديد في نصوص الوحي وقراءها قراءة جديدة في ضوء المعطيات المعرفية والاجتماعية المتجددة.

دكتوراه في العلوم السياسية من جامعة وين (Wayne) بولاية ميتشيغان الأمريكية. أستاذ العلوم السياسية المشارك في الجامعة 
لقد سعينا في بحثنا هذا إلى تتبع جذور الحخلاف الذي أدى إلى بروز إشكالية تعارض العقل والنقل، ووجدنا أن الإشكالية قد تولدت نتيجة للصراع الفكري بين الاتحاهين الحشوي والابحاه الكلامي. لذلك ترك خلصنا إلى أن التعارض بين العقل والنقل في فحواه تعارض بين عقلين، أو بين منظومتين متباينتين من الأحكام، تم تطويرهما انطلاقاً من منهجيتين معرفيتين مختلفتين، واعتماداً على بنيتين معرفيتين متغايرتين. كذلك أكدنا ضرورة تطوير عقلية تكاملية تتكامل فيها المعرفة المستمدة من الرؤية القرآنية والمعرفة الناجمة عن بـن الخبرة الإنسانية، وشددنا على أن العملية التطويرية هذه شرط ضروري لتجاوز إشكالية التعارض، والمضي في معارج الارتقاء العلمي والمعرين، والتأهب للقيام بالفعل الحضاري الإسلامي المرتقب.

\section{إشكالية التعارض}

تتحدد الصورة العامة لإشكالية التعارض في عبارة أوردها ابن تيمية في مطلع كتابه "درء تعارض العقل والنقل"، ونسبها إلى فخر الدين الرازي: "إذا تعارضت الأدلة السمعية والعقلية، أو السمع والعقل، أو النقل والعقل، أو الظواهر النقلية والقواطع العقلية، أو نحو ذلك من العبارات، فإما أن يُجمع بينهما، وهو محال، لأنه جمع بين النقيضين، وإما أن يردا جميعاً، وإما أن يقدم السمع، وهو محال، لأن العقل أصل النقل فلو قدمناه عليه كان ذلك قدحاً في العقل الذي هو أصل النقل، والقدح في أصل الشيء قدح فيه، فكان

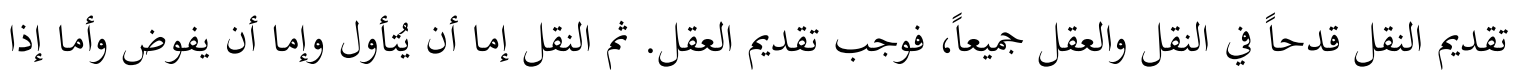
تعارضا تعارض الضدين امتنع الجمع بينهما ولم يمتنع ارتفاعهما". 1 فالإشكالية كما يتضح من العبارة

أحمد بن تيمية: درء تعارض العقل والنقل، تحقيق محمد رشاد سالم، الرياض: جامعة الإمام محمد بن سعود الإسلامية، 1399هـ

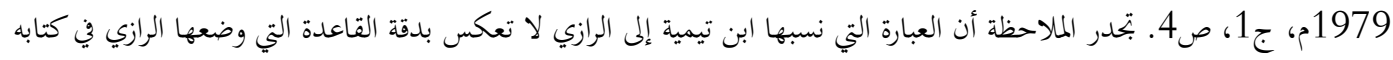

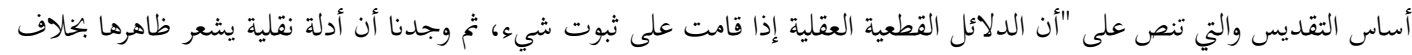

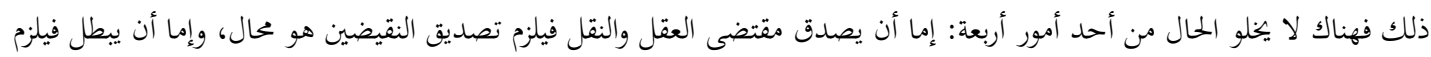

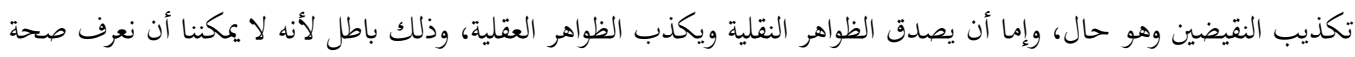

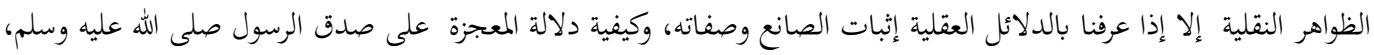

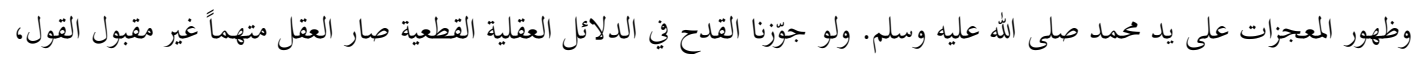

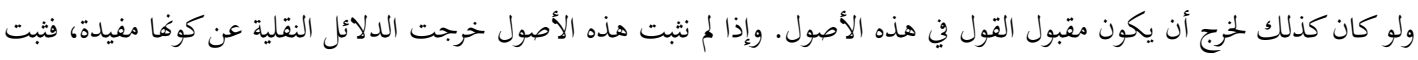

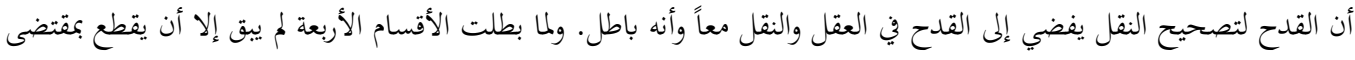

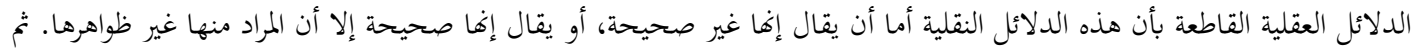

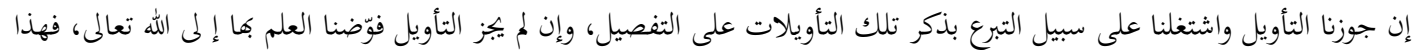


السابقة، تتعلق بتحديد الكيفية الواجب اتباعها لتجاوز التعارض أو التناقض بين الأحكام النقلية والأحكام العقلية حال قيامه. ولأن القاعدة التي اعتمدها الرازي للتعامل مع مشكلة تعارض العقل والنقل تقتضي تقديم العقل على النقل على أساس أن العقلَ أصلُ النقلِ، فإن ابن تيمية يعمد في كتابه هذا إلى تفنيد قاعدة تقديم العقلي على النقلي وإظهار فسادها، لينتهي أخيراً إلى استحالة قيام تعارض حقيقي بين القطعيات النقلية والعقلية، وبالتالي إلى ضرورة "دفع المعارض العقلي" حال قيامه والحكم عليه بالفساد. 2 وبذلك يحدد ابن تيمية موقفه من إشكالية التعارض باتخاذ موقف مناقض لموقف الرازي، والدعوة إلى تقديم النقل على العقل حال تعارضهما، فيقول: "إذا تعارض الشرع والعقل وجب تقديم الشرع، لأن العقل مصدق للشرع في كل ما أخبر به، والشرع لم يصدق العقل في كل ما أخبره به". 3

بيد أن ابن تيمية يلحظ أن القول بقيام تعارض بين نقل يُردُّ إلى الوحي المنزل من لدن حكيم خبير، وعقل جعله الوحي نفسه مدار التكليف أمر مشكل في ذاته، لذلك يكرر في سياق نقده للرأي القائل بتقديم العقل على النقل القول بأن التعارض لا يمكن أن يقوم بين القطعي من أحكام العقل والنقل. وإذا كان ذلك كذلك فإن التقديم يجب أن يرتبط بقطعية الحكم مهما كان مصدره. لذا يدعو ابن تيمية إلى تقديم قطعيين فيمتنع التعارض، وإن كانا ظنيين فالراجح هو المقدّم". 4

هل يعني هذا أن الإشكالية قد حلت وأن بالإمكان تقديم العقلي القطعي على النقلي الظني؟ هنا نجد ابن تيمية يتردد في موقفه ويتحفظ على تأخير النقلي الظني، فيقول: "فإن قيل نحن نستدل بمخالفة العقل للسمع على أن دلالة السمع المخالفة له باطلة، إما لكذب الناقل عن الرسول، أو خطئه في النقل، وإما لعدم دلالة قوله على ما يخالف العقل محل النزاع، قيل هذا معارض بأن يقال نحن نستدل بمخالفة العقل للسمع على أن دلالة العقل المخالفة له باطلة لبطلان بعض مقدماته، فإن مقدمات الأدلة العقلية المخالفة

هو القانون الكلي المرجوع إليه في جميع المتشاجات وبالله التوفيق". انظر أساس التقديس، تحقيق الدكتور أحمد حجازي السقا، القاهرة:

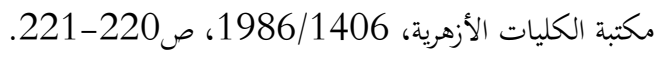

$$
\begin{array}{r}
2 \\
\text { 4 }
\end{array}
$$


للسمع فيها من التطويل والخفاء والاشتباه والاختلاف والاضطراب ما يوجب أن يكون تطرق الفساد إليها أعظم من تطرقه إلى مقدمات الأدلة السمعية". 5

وهكذا يأخذ الخلاف بين العقلي والنقلي بُعداً جديداً. فالقضية ليست قضية تقديم لقطعي وتأخير لظني، بل قضية إثبات منهج في النظر والاستدلال في مقابل منهج آخر وترجيح "معقول" نقلي في مواجهة "منقول" عقلي. لذا نرى ابن تيمية يؤكد مرجعية العقل في إثبات صدق الوحي والنبوة، ولكنه ينزع منه الحق

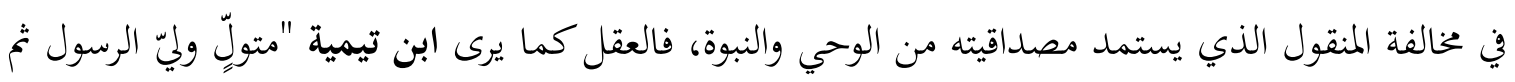
عزل نفسه، لأن العقل دل على أن الرسول صلى الله عليه وسلم يجب تصديقه فيما أخبر، وطاعته فيما أمر".

إن تراجع ابن تيمية عن القاعدة التي اختارها آنفاً والتي تقضي بتقديم القطعي، سواء أكان عقلياً أم نقلياً، يعود في تقديرنا إلى إدراكه أن التعارض بين العقلي والنقلي ليس تعارض بين منظومتين من الأحكام التي تم الوصول إليهما وفق منهجين مختلفين، أو لنقل توخياً للدقة هو تعارض بين عقلين، كما صرح بذلك ابن تيمية عندما وصف التعارض بين العقلي والنقلي أنه "تعارض العقل الدال على صدق الرسول والعقل المناقض لخبر الرسول". فإصرار ابن تيمية على إخضاع العقلي إلى حكم النقلي يرجع إلى رغبة قوية في التصدي للعقلانية الكلامية التي يمثلها الرازي والغزالي والجويني وغيرهم من أعلام المتكلمين. فالقانون الكلي الذي يدعو إلى تقديم العقل على النقل عند قيام التعارض بينهما لم يضعه الرازي، كما يخبرنا ابن تيمية، بل سبقه أبو حامد الغزالي إليه. وبدهي أن "العقل المناقض لخبر الرسول" الذي يشير إليه ابن تيمية ليس عقلاً رافضاً لأولوية أحكام الكتاب، لأن الخصم الذي يواجهه ويتصدى لمقولاته هو المدرسة الكلامية المقرة بصدق الرسالة والمنافحة عنها ضد المتشككين في مرجعيتها، بل العقل المصر على استبعاد الحبر الظني من دائرة المرجعية التصورية. لذلك نرى ابن تيمية يشدد على رفض تحكيم العقلي في المنقول الظني، فيقول في معرض الرد على من يدعو إلى استبعاد الخبر لضعف إسناده أو اضطراب متنه: "فإن قالوا إنما أردنا

$$
\text { } 6 \text { } \quad \text { المصدر نفسه، ص174؟ }
$$


معارضة ما يظن أنه دليل وليس بدليل أصلاً، أو يكون دليلاً ظنياً لتطرق الظن إلى بعض مقدماته، إما في الإسناد وإما في المتن، كإمكان كذب المخبر أو غلطه، وكإمكان احتمال اللفظ لمعنيين فصاعداً، قيل إذا فسرتم الدليل السمعي بما ليس بدليل في نفس الأمر، بل اعتقاد دلالته جهل، أو بما يظن أنه دليل وليس بدليل، أمكن أن يفسر الدليل العقلي المعارض للشرع بما ليس بدليل في نفس الأمر، بل اعتقاد دلالته جهل، أو يظن أنه دليل وليس بدليل".

يتضح لنا من النقاش السابق أن إثكالية التعارض لا تتعلق بالتشكيك في أهمية الوحي والعقل لتوجيه

الحياة البشرية، فكلا الفريقين متفقان على ضرورة اتباع الأحكام القطعية، سواء انتسبت إلى الوحي أو العقل، واستحالة قيام تعارض بين القطعيات العقلية والنقلية. بل تتعلق الإشكالية بتعارض عقليتين أو منهجين في التفكير والاستدلال. فالرازي لا يشكك في كون الوحي مصدراً معرفياً، بل ينطلق من النص القرآي في تحديد التصور الكلي للوجود، كما فعل في كتابه أساس التقديس. لكنه يدعو إلى تأويل نصوص الكتاب إذا استحال حمل معناها على ظاهرها، وإلى رد أخبار الآحاد عند تعارضها مع أحكام العقل القطعية. وبالمثل فإن ابن تيمية لا يتشكك في أهمية مبادئ العقل في بيان صدق المنقول، لكنه لا يرى أن كل ما نسب إلى العقل قطعي لا يحتمل التردد فيه.

إن المواجهة بين ابن تيمية والرازي، التي تعرضنا إلى طرف منها في الفقرات السابقة، ليست مواجهة بين شخصين، بل بين تيارين فكريين كبيرين. ذلك أن الموقفين الرئيسيين من مسألة تعارض العقل والنقل المتمثلين في آراء الرازي وابن تيمية يعبران عن حالة الاستقطاب التي صبغت حركة تطور الفكر الإسلامي خلال القرون الماضية وأدت إلى انقسام العلوم إلى نوعين متمايزين ومتصارعين: العلوم العقلية والعلوم الدينية. لذلك فإننا نلحظ الصراع المتدم بين العلوم العقلية والدينية في كتابات أبي حامد الغزالي، أحد أبرز رجالات المدرسة الأشعرية التي حملت شعلة العقل الكلامي بعد المعتزلة. إذ يعمد الغزالي في مقدمة كتابه الأصولي الهام المستصفى من علم الأصول إلى تقسيم العلوم إلى عقلية ودينية، فيقول في معرض الحديث عن مرتبة علم 
الأصول بين سائر العلوم: "اعلم أن العلوم تنقسم إلى عقلية كالطب والحساب والهندسة وإلى دينية كالكلام والفقه وأصوله وعلم الحديث وعلم التفسير وعلم الباطن". 9

وعلى الرغم من تأكيد الغزالي المستمر أهميةً العقل، واعتباره "الحاكم الذي لا يعزل ولا يبدل، وشاهد

الشرع المزكى المعدل"، 10 فإن تقسيم العلوم إلى عقلي وديني دفع الغزالي إلى تمميش العلوم العقلية. فالعلوم العقلية، كما يرى الغزالي، تنقسم إلى "عقلي محض لا يحث الشرع عليه ولا يندب إليه، كالحساب والهندسة والنجوم وأمثاله من العلوم فهي بين ظنون كاذبة لائقة، وإن بعض الظن إثم، وبين علوم صادقة لا منفعة لها، ونعوذ بالله من علم لا ينفع، وليست المنفعة في الشهوات الحاضرة والنعم الفاخرة، فإنها فانية دائرة، بل النفع

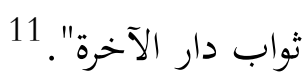

\section{حركة الفكر الإسلامي بين النقلي المعقول والعقلي المنقول}

إن إشكالية تعارض العقل والنقل لم تنبع أصلاً من داخل العقل الإسلامي الذي تشكل بتأثير الخطاب القرآني، ولكنها طرأت نتيجة لتأثر الفكر الإسلامي بالعقل الإغريقي الثاوي في الفلسفات الإغريقية. ذلك أن المدقق في الخطاب القرآني يلحظ استنكار القرآن الشديد للعقلية الآبائية الرافضة للوحي المنزل استناداً إلى مرجعية تاريخية وأحكام موروثة عن الأجيال:

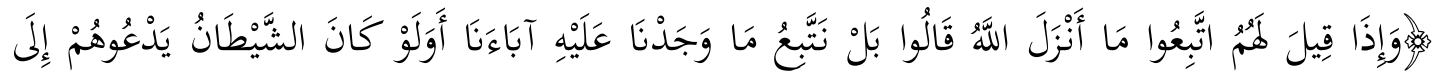

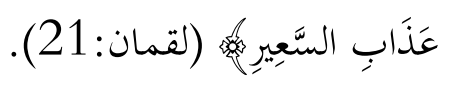

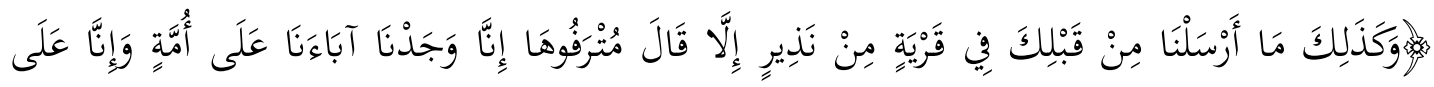

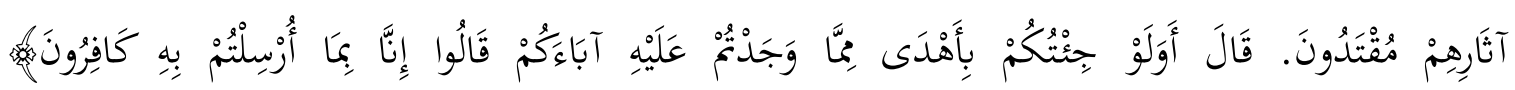
(الزخرف:23-24)

$$
\begin{aligned}
& 10 \\
& 11
\end{aligned}
$$




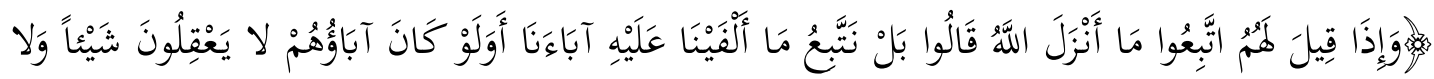

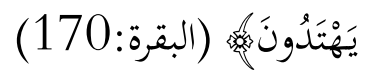

وانبنى التنديد القرآني بالموقف الآبائي على أن هذا الموقف يعكس رؤية منغلقة على ذاتا رافضة للنظر في أطروحات الخطاب المنزل وتعقل مضمونه، والحكم عليه من خلال تقويم حتواه قياساً بحتوى التصور الموروث عن الآباء. كما دعا القرآن مشركي قريش إلى تأسيس تصوراقم ومعتقداقم على قاعدة معرفية ثابتة، وعلى يقين علمي نابع من نظرة ناقدة متفحصة:

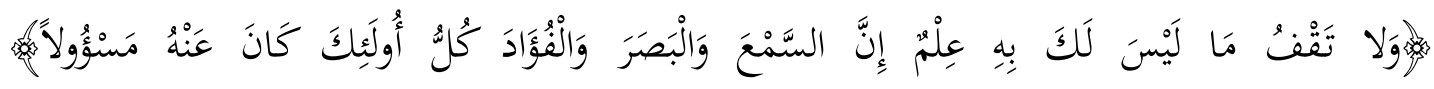

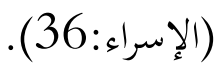

فقدرة الإنسان على السمع وفهم الخطاب والنظر في الآيات المبثوثة في الآفاق الممتدة من حوله، ومن ثَّم الوصول إلى قناعات علمية راسخة بما يملكه من عقل أو فؤاد هي التي تمكنه من الوصول إلى الحقائق. فالعقل قادر على اكتشاف عظمة الخالق من خلال النظر إلى المخلوق والتفكّر في آياته:

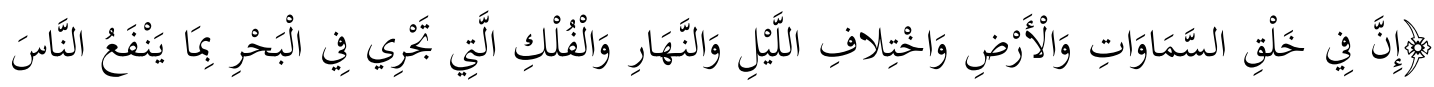

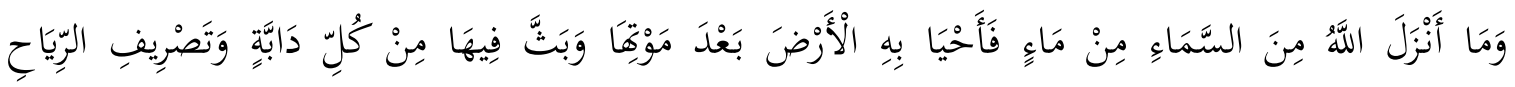

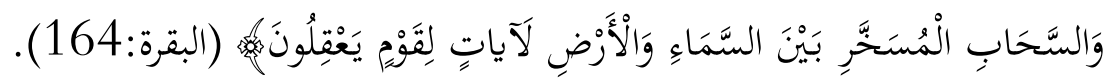
فالقرآن يدعو الإنسان إلى الاستدلال على وحدة الله وجلاله وقدرته بالنظر إلى ملكوته والتأمل في آياته. كذلك يدعو القرآن الإنسان إلى التصديق بمرجعيته الإلهية وإلى التيقن بعصديته العلوية من خلال تدبر آياته والتأمل في تماسك عباراته واتساق معانيه:

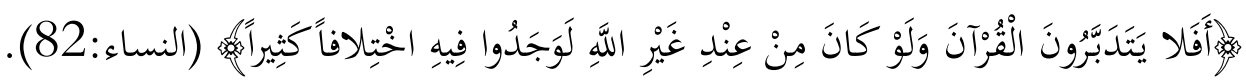
وطالب القرآن الخصوم أن يقدموا برهاغم على صدق معتقداقم وأن يينوا مصدر علمهم: 


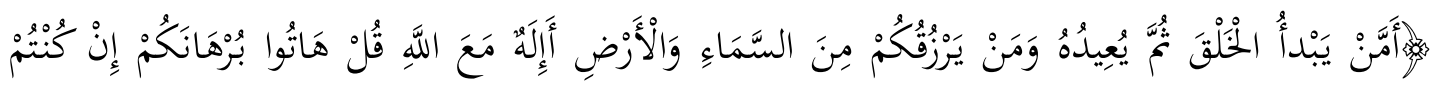

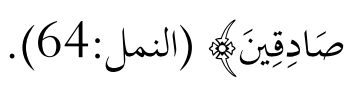

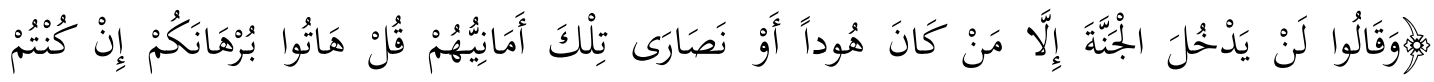

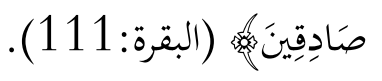

وانطلاقاً من النظرة القرآنية التي تربط العقل بقدرة الإنسان على تمييز الحق من الباطل والخير من الشر، رأى علماء المسلمين الأوائل أن للعقل قدرة فطرية أو غريزة تمكن الإنسان من النظر واكتساب المعارف

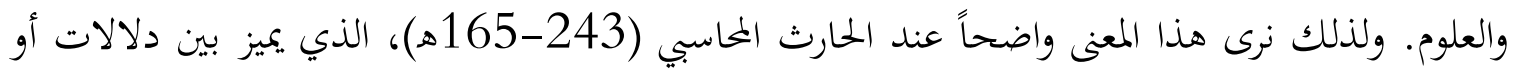
مستويات ثلاثة للعقل. فالعقل أولاً غريزة يولد العبد بها ثم يزيد فيها معنى بعد معنى بالمعرفة بالأسباب الدالة الدارئ

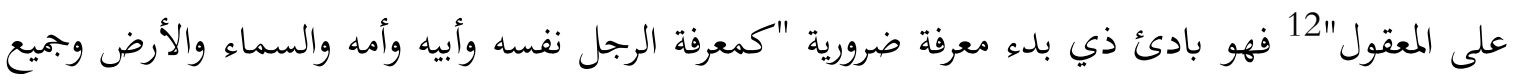

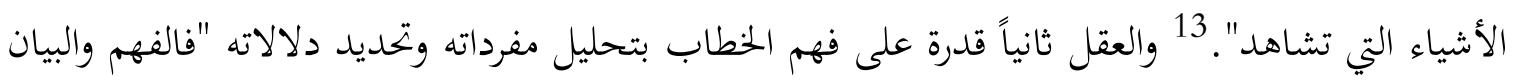

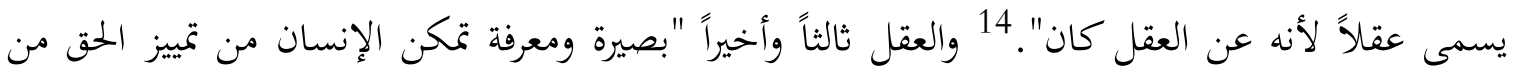
الباطل والصواب من الخطأ والمصلحة من المضرة. ومع قدرة الإنسان على التمييز بين الخير والشر فإن العاقل هو الذي يلزم الخير ويتجنب الشرور، ويقبل الحق ويرفض الباطل". 15 بيد أن المفهوم السابق للعقل على أنه النه قدرة فطر الله الناس عليها تمكنهم من تمييز الصدق من الكذب والحق من الباطل، على بساطتها، لم تلبث أن اضطربت مع انتشار الفلسفات الإغريقية، وما حملته من مفاهيم ما ورائية مرتبطة بالتصور الإغريقي للوجود. فنجد أن الفلاسفة المسلمين الأوائل تبنوا النظرية الإغريقية للوجود، واعتمدوها في كتاباقم. فالفارابي

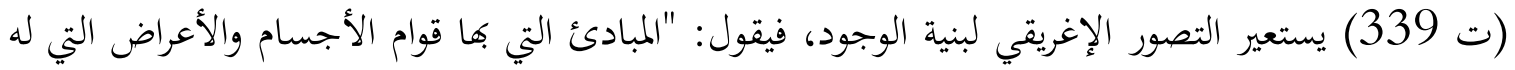
ستة أصناف، لها ست مراتب عظمى، كل مرتبة منها تحوز صنفاً منها؛ السبب الأول في المرتبة الأولى، الأسباب الثواني في المرتبة الثانية، العقل الفعّال في المرتبة الثالثة، النفس في المرتبة الرابعة، الصورة في المرتبة

$$
\begin{aligned}
& 12 \text { 1 الحارث بن أسد المحابي: شرف العقل وماهيته، تحقيق مصطفى عطا، بيروت: دار الكتب العلمية، 1406هـ1986م، ص20 } \\
& 13 \\
& 14
\end{aligned}
$$

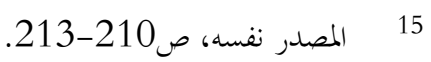


الخامسة، المادة في المرتبة السادسة". 16 وتتولد عن نظرية الوجود هذه نظرية معرفة للعقل الفعال فيها أثر رئيسي في توليد معارف جديدة. فالعقل الفعّال هو الذي يمكن الإنسان من تعقل الأجسام التي ليست بذواتما معقولات، لأن "المعقولات بذواتما هي الأشياء المفارقة للأجسام، والتي ليس قوامها في مادة أصلاً". 17 ومن خلال تحويل صور الأجسام إلى معقولات ثم تلقينها للعقل الإنساني، يتحول هذا الأخير من عقل بالقوة إلى عقل بالفعل. لذلك يؤكد الفارابي أن "القوة الناطقة التي بها الإنسان إنسان ليست هي في جوهرها عقلاً بالفعل، ولم تعط بالطبع أن تكون عقلا بالفعل، ولكن العقل الفعال يصيرها عقلاً بالفعل، ويبعل سائر الأشياء معقولة بالفعل للقوة الناطقة". 18 وهكذا يقوم الفارابي بإعادة تفسير الحقل المعريف الإنساني انطلاقاً من فرضية العقل الفعّال والمعقولات المفارقة الناجمة عن فعله وبإعادة تفسير ظواهر الوجود، بما فيها ظاهرة الوحي والألوهية. فالموجودات التي تحتل رتبة أعلى من العقل الفعّال لا تعقل إلا ذواتا. بينما يتفرد العقل البشري من بين الأنفس العاقلة بتعقل المادة، بهدي من العقل الفعّال. والعقل الفعّال الذي يمثل الفيض الإلهي هو الوحي الذي يهدي الإنسان إلى معرفة الحق. "فهذه الإفاضة الكائنة من العقل الفعّال إلى العقل المنفعل بأن يتوسط بينهما العقل المستفاد هو الوحي". 19

وحاول ابن سينا أن يطور التصور الإغريقي لسيرورة التعقل، فأدخل مفاهيم جديدة، مثل "العقل الهيولي" و"العقل القدسي"، لكنه احتفظ بفرضية العقل الفعّال. لذلك أطلق ابن سينا على قدرة النفس الفطرية على توليد التصورات والمفاهيم اسم العقل الهيولي، بينما أطلق اسم "العقل بالملكة" على المقدمات الأولية البديهية، "مثل اعتقادنا بأن الكل أعظم من الجزء، وأن الأشياء المساوية لشيء واحد متساوية". 20 وشدد ابن سينا على أن العقلين الهيولي وبالملكة عقلان بالقوة لا بالفعل، وزعم أن تحولما من القوة إلى

16 أبوالنصر الفارابي: كتاب السياسة المدنية الملقب بمبادئ الموجودات، تحقيق فوزي متري نجار، بيروت: دار المشرق، 1993م، ص31.

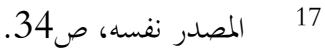
18 المصدر نفسه، ص35.

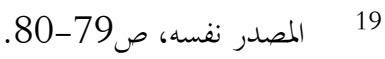
202 
الفعل يتم بتأثير العقل الفعّال. وينتج عن عملية التحول هذه ظهور "العقل المستفاد"، وهو بجموعة المعارف والعلوم المكتسبة بالنظر والتعلم.21

وفي مواجهة المد الفلسفي الإغريقي المصرِّ على كفاية العقل في فهم حقائق الوجود، والجانح إلى تطويع دلالات الوحي إلى مقولات الفلسفة الإغريقية، برز المتكلمون للتصدي لشطحات العقل الإغريقي، ولإعادة ترتيب نظرية الوجود ونظرية المعرفة وفق دلالات الوحي. لذلك رفض المتكلمون دعوى كفاية العقل وأكدوا ضرورةً اعتماد الوحي مصدراً (أو دليلاً) معرفياً إلى جانب العقل. فنجد مثلاً أن الجويني يقسم الأدلة إلى سمعي وعقلي: "الأدلة التي يتوصل بصحيح النظر فيها إلى ما لا يعلم في مستقر العادة اضطراراً، وهي تنقسم إلى قسمين: العقلي والسمعي. فأما العقلي من الأدلة، فما دل بصفة لازمة هو في نفسه عليه، والسمعي هو

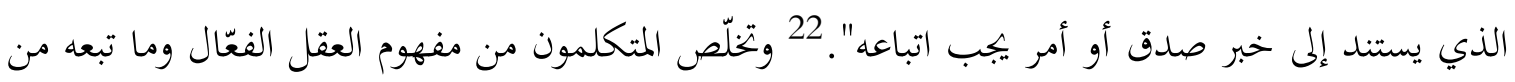
عقول لواحق. فالعقل قسمان: غريزي ومكتسب. ويتألف القسم الغريزي -الذي هو العقل الحقيقي المتقدم على النظر - من "جملة العلوم الضرورية". 23 وهذه العلوم الضرورية إما أن تكون من مدركات الحواس التي تنطبع في النفوس ابتداءً، أو من الاوليّات التي فطرت عليها النفوس. "فأما ما كان واقعاً عن دَرْكَ الحواس فمثل المرئيات المدركة بالنظر، والأصوات المدركة بالسمع، والطعوم المدركة بالذوق، والروائح المدركة بالشم، والأجسام المدركة باللمس [...] وأما ما كان مبتدئاً في النفوس فكالعلم بأن الشيء لا يخلو من وجود أو عدم، وأن الموجود لا يخلو من حدوث أو قدم، وأن من المحال اجتماع الضدين، وأن الواحد أقل من الاثنين. وهذا النوع من العلم لا يجوز أن ينتفي على العاقل مع سلامة حاله وكمال عقله". 24 ومن العقل الفطري الضروري تتولد المعارف والعلوم وتتنامى بازدياد الخبرة ودقة الملاحظة والفطنة: "وأما العقل المكتسب فهو نتيجة العقل الغريزي وهو غاية المعرفة، وصحة السياسة، وإصابة الفكر. وليس لهذا حدٌّ

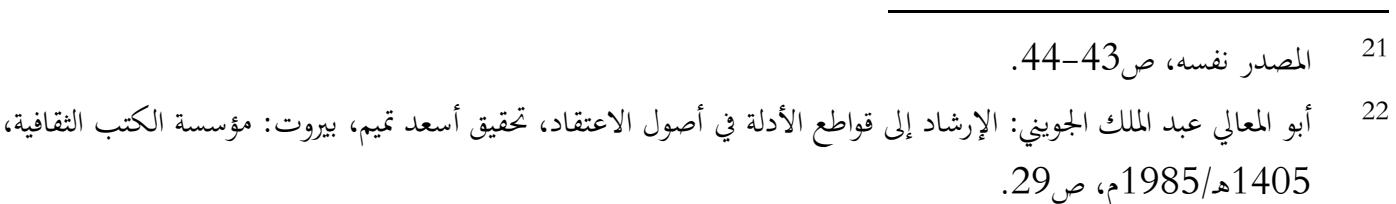

المصدر السابق، ص36-37-37. انظر أيضاً علي بن محمد الماوردي: أدب الدنيا والدين، تحقيق محمد صباح، بيروت: دار مكتبة الحياة،

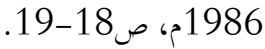
24 ا الماوردي: أدب الدنيا والدين، مصدر سابق، ص1986. 
لأنه ينمو إذا استعمل وينقص إذا أهمل. ونماؤه يكون بأحد وجهين: إما بكثرة الاستعمال إذا لم يعارضه مانع من هوى ولا صَادٌّ من شهوة، كالذي يحصل لذوي الأسنان من آراء الشيوخ [...] وإما [...] بفرط الذكاء وحسن الفطنة، وذلك جودة الحدس في زمان غير مهمل للحدس. فإذا امتزج بالعقل الغريزي صارت نتيجتهما نمو العقل المكتسب، كالذي يكون في الأحداث من وفور العقل وجودة الرأي". 25

إن الإسهام الكبير الذي قدمه الفكر الإسلامي لإنضاج مفهوم العقل وتحديد حدوده ومصادره يتمثل في ربط عمليات العقل ومبادئه بالواقع الحسي والنص الموحى. فقد أدى تطور البحث في نظرية الوجود ونظرية المعرفة إلى رفض علماء المسلمين المنهج الإغريقي في التوليد المعريز المنحصر في عمليات تأمل نظري داخل منظومة منغلقة من الأحكام، وأصروا على ربط المعرفة بالتجربة والملاحظة. كما رفضوا دعوى الفلاسفة الإغريق بكفاية العقل وقدرته على النظر في بينة المغيَّب الماورائي دون الرجوع إلى الوحي المنزل من لدن عليم خبير.

لقد استطاع الفكر الإسلامي في مرحلة نضجه في القرنين الخامس والسادس الهجريين من تطوير تصور دقيق للعقل وآليات التفكير، تجاوزت الأطروحات الإغريقية المنبنية على نظرية الفيض. فنرى بدايات بتحاوز الفكر الإسلامي لأطروحة العقل الفعّال في كتابات ابن رشد. فابن رشد يظهر في رسالة ما بعد الطبيعة أن إدراك العقل للأشياء الحسية المخيطة به يتم نتيجة لعملية تحديد الصفات الكلية التي تجمع المدركات الحسية الجزئية، وأن الكليات لذلك ذات طبيعة ذهنية وأخها غير مفارقة للنفس المدركة أو الشيء المدرك. ذلك أن افتراض وجود خارجي مفارق للكليات يقتضي استحالة تعلق الكليات بجزئيات، لأن الكلي من شأنه أن يحمل على كثيرين. فالكلي المعقول ناجم عن عملية ذهنية يتم خلالها انتزاع الوصف المشترك بين الجزئيات. فالقول بمفارقة الكليات للعقل المدرك غير لازم لفهم عملية الإدراك كما يؤكد ابن رشد: "وأما الذين يضعون هذه الكليات جواهر قائمة بأنفسها ومفارقة، فإنه يلزمهم أن تكون غير الأشياء المفردة بوجه ما، وإذا وضع هكذا لزمهم أحد أمرين: إما أن تكون تلك الكليات ليست هي معقولات هذه الأشياء المفردة، فيكون لا غناء لها في تصور هذه المفردة، وهذا ضد ما يقولون لأفم إنما أدخلوا المفارقة وقالوا بها من أجل المعرفة، أو 
نسلم لهم أن تلك الكليات هي التي تعرف جواهر هذه المفردات، وأن بها تعقل ماهيات هذه، ولكن متى كان هذا أيضاً هكذا لزم أن تكون هذه الكليات المفارقة من جهة ما هي موجودة خارج النفس ومغايرة في وجهة ما تغاير الأشياء التي خارج النفس بعضها بعضاً محتاجة أيضاً في أن تعقل إلى كليات أخر، إلى غير هاية. فظاهر من هذا أنا لسنا نحتاج في أن نعقل ماهيات الأشياء إلى القول بوجود كليات مفارقة سواء كانت موجودة أو لم تكن، بل إن كانت موجودة فليس يكون لها غناء في عقل ماهيات الأشياء، ولا بالجملة

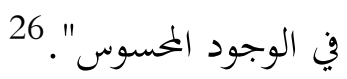

بيد أن ابن رشد يعود إلى القول بوجود جواهر مفارقة للكليات خارج العقل، وإلى قبول التقسيم الإغريقي لبنية الوجود إلى مستويات ستة، وإلى الحديث عن امتلاك الأجرام السماوية المتحركة لعقول و تأثيرها في الموجودات الموجودة في المستويات المتدنية، وإلى البحث في العقل الفعّال وتأثيره في الموجودات الواقعة دون فلك القمر. 27 ويعود احتفاظ ابن رشد بالعديد من الأطروحات الإغريقية عن عقول مفارقة، في تقديرنا، إلى الحاجة إلى عقل مفارق لتفسير معقولية الطبيعة. فقدرة العقل الإنساني على تجريد الكلي من الجزئي وتحديد ماهيات الأشياء يعود إلى انبناء الأشياء أصلاً على أساس عقلي، فوجب لذلك قيام عقل مفارق للشيء المعقول وللعقل الإنساني. فكما أن إدراكنا لصورة البيت ناجم عن عملية تجريد ذهني للصفات المشتركة في المدركات الحسية -إذ أن قيام البيت بالفعل ناجم عن قيام صورته أولاً في عقل البنّاء- فإن إدراكنا للأشياء الطبيعية الموجودة بالفعل ناجم عن قيام صورة الأشياء في عقل مفارق للأشياء نفسها ولعقولنا معاً. "ولذلك قيل إن أول الفكرة آخر العمل وأول العمل آخر الفكرة. ويشبه أن يكون الأمر في الأشياء الطبيعية هكذا، وأن يكون مبدؤها الأقصى التصور بالفعل. وإلا فمن أين عرض لها أنت تكون في طبيعتها مستعدة لأن نعقلها نحن، فإن ذلك لها أمر ذاتي وموجود في طباعها. والأمر الذاتي إنما يكون حصوله للموجود عن سبب فاعل ضرورة، وليس هاهنا شيء يصير به المحسوس معقولاً بالقوة، أي في طباعه أن يعقله إلا أن يكون تكونه عن تصور عقلي، وإن كان وجوده محسوساً عن مبادئه المحسوسة". 28 ولو أن ابن رشد التزم بالتصور الكلي

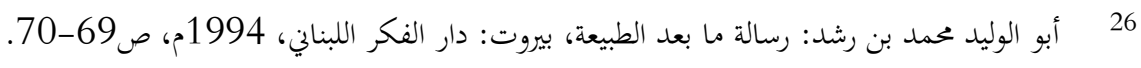

$$
\begin{aligned}
& 27 \text { المصدر السابق، ص136-130-160. } \\
& 28
\end{aligned}
$$


القرآي لرد صور الأشياء ونظمها إلى تقدير عليم خبير قدير. فتقدير الأشياء في علم الله تعالى هو مصدر بنيتها الشكلية ومادتما المضمونية، وبالتالي طبيعتها العقلية وانتظامها البنيوي. فإدراك العقل لبنية الطبيعة وصور الأشياء ناجم عن قدرات العقل التحليلية والتركيبة والتجريدية الهادفة إلى استشفاف التقدير الإلهي للوجود في النفس والمجتمع والطبيعة. فالعلم البشري ليس سوى محاكاة للعلم الإلهي.

وبحلول القرن السادس الهجري استطاع الفكر الإسلامي أن يتجاوز الأطروحات الإغريقية جميعاً في تطويره لنظرياته المعرفية. لذلك نجد عالماً جليلاً مثل فخر الدين الرازي يبين بوضوح أن عملية الإدراك لا تتعلق من قريب أو بعيد بنظرية الفيض التي تردّ انتقال العقل الإنساني من القوة إلى الفعل أو من العقل الهيولي إلى العقل المستفاد، بل ترتبط بعملية تجريد الصور العقلية المرتسمة في الذهن من العوارض والاحتفاظ بالعناصر المشتركة التي تشكل ماهية الشيء المعقول. فالإدراك العقلي عملية تجريد ذهني وليست انتقال معقول خارجي إلى الذهن: "اعلم أن النفس لا شك في كوغا مستعدة للانتقاش بصورة الموجودات، لكن الاستعداد اللازم لوجودها الحاصل لها في أول الأمر غير كافٍ ولا تام؛ فإن ذلك الاستعداد لو كان تاماً وقد ثبت أن الفيّّاض لتلك التعقلات عام الفيض لا تتخصص إفاضته بوقت دون وقت لأمر عاد إليه، بل لما يعود إلى القوابل والمستعدات، وجب أن تكون تلك التعقلات والمعارف حاصلة لها في أول الأمر، وأن لا توجد النفس خالية عن شيء منها. وإذا ليس الأمر على هذا الوجه علمنا أن الاستعداد المصاحب لها في أول الفطرة غير كافٍ في فيضان تلك التعقلات عليها من مبادئها. فإذاً لا بد من زيادة استعداد لها حتى تحدث لها تلك الصورة وتلك الزيادة أمر حادث فلا بد له من سبب حادث لما عرفت أن كل حادث فلحادث آخر قبله وليس ذلك إلا الإحساس بالجزئيات، فإن الإحساس .ها سب لتنبه النفس لمشاركات تلك الأمور المحسوسة ومبايناتا، وذلك سبب لانتقاش النفس بالتصورات الكلية المجردة عن العوارض المادية ولواحقها، والشعور بما لها من الذاتيات والعرضيات، لازمة كانت أو مفارقة، بطيئة الزوال كانت أو سريعة. فالنفس تنتفع بالحس في اكتسابها للتصورات من هذا الوجه". 29

$$
29 \text { فخر الدين الرازي: المباحث المشرقية في علم الإلهيات والطبيعيات، تحقيق محمد المعتصرم بالله البغدادي، بيروت: دار الكتاب العربي، }
$$


وهكذا يخلص الرازي إلى تحديد العقل بعناصر أربعة، ثلاثة منها فطرية وواحد مكتسب: 1التصورات والتصديقات الحاصلة للنفس بالفطرة، 2- العلوم الأولية أو الضرورية التي تمثل مبادئ التفكير البدهية، 3- "القوة القدسية" المتمثلة بتمييز النفس بكثرة الأوليات وامتلاكها لمعارف كثيرة قبلية، 4- العلوم النظرية، وهي علوم مكتسبة بالتجربة والتعلم.

\section{العقل والمعرفتان القيمية والغيبية}

لقد شغلت مسألة العقل وقدراته وطرائق اكتسابه للمعارف والعلوم الفكر الإسلامي لقورن طويلة، واستطاع هذا الفكر بعد لأيٍ أن يتجاوز الأطروحات الإغريقية. لقد تأثر الفكر الإسلامي في بداية ظهوره بالفكر الإغريقي تأثراً كبيراً. وكما رأينا من قبل فقد استعار الفلاسفة المسلمون الأوائل كثيراً من مضامين الفكر الإغريقي في تطوير نظريتي الوجود والمعرفة بعد إدخال تعديلات طفيفة لتقريبها إلى الرؤية الإسلامية للوجود. ولم ينج من تأثير الفكر الإغريقي علماء الكلام أنفسهم الذين برزوا للتصدي للفلاسفة وإظهار قافت أطروحاقم. فقد أصر المعتزلة على أن العقل قادر على التمييز بين الحسن والقبيح، وجعلوه مصدراً (أو دليلاً) معرفياً مكافئاً للكتاب والسنة ومقدماً عليهما. لذلك أكد القاضي عبد الجبار في فصل عقده لبيان الأدلة الواجب اتباعها أن العقل أول هذه الأدلة، "لأن به يميّز بين الحسن والقبيح، ولأن به يعرف أن الكتاب حجة، وكذلك السنة والإجماع. وربما تعجب من هذا الترتيب بعضهم، فيظن أن الأدلة هي الكتاب والسنة والإجماع فقط، أو يظن أن العقل إذا كان يدل على أمور فهو مؤخر، وليس الأمر كذلك، لأن الله تعالى لم يخاطب إلا أهل العقل، ولأن به يعرف أن الكتاب حجة، وكذلك السنة والإجماع، فهو الأصل في هذا الباب. وإن كنا نقول إن الكتاب هو الأصل من حيث أن فيه التنبيه على ما في العقول، كما أن فيه

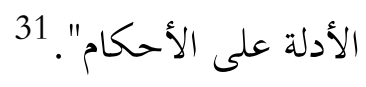

وفي مواجهة الموقف المعتزلي الذي يعطي العقل القدرة على التحسين والتقبيح، ويجعل حكمه مكافئاً لحكم الوحي، نفى الأشاعرة أن يكون العقل قادراً على تمييز الحسن من القبيح. فنرى الجويني يصر على أن

$$
\begin{aligned}
& 30 \text { 30 }
\end{aligned}
$$

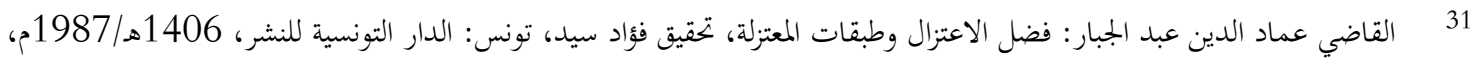


"العقل لا يدل على حسن شيء ولا قبحه في حكم التكليف، وإنما يتلقى التحسين والتقبيح من موارد الشرع وموجب السمع. وأصل القول في ذلك أن الشيء لا يحسن لنفسه وجنسه وصفة لازمة له. وكذلك القول فيما يقبح، وقد يحسن في الشرع ما يقبح مثله المساوي له في جملة أحكام صفات النفس". 32 ويستشهد الجويني للتدليل على صحة موقفه بأن "البراهمة كما وافقوا المعتزلة في التحسين والتقبيح العقليين على زعمهم، فكذلك اعتقدوا قبح ذبح البهائم والتسليط على إيلامها، وتعريضها للنصب والتعب". 33 لقد أخطأ عبد الجبار عندما جعل العقل دليلاً معرفياً، وأعطاه القدرة على التحسين والتقبيح، وجعل الوحي مصدقاً للعقل في حكمه. ذلك أن العقل في أساسه الفطري وطبيعته الجبلّية ليس سوى نسق من المبادئ المنطقية (مثل الاتساق والسببية) والعمليات الإجرائية (مثل التحليل والتركيب والتجريد والتشخيص)؛ وهو لذلك يستمد مضامينه المعيارية ومحتواه المعرفي من خلال تمثله الثقافي والتربوي وخبرته المعرفية والميدانية، أو من خلال وعيه بالتناقضات الداخلية للأفكار المكتسبة، والتناقضات الخارجية بين الفكر والواقع. 34 فالحك على قبح الأفعال أو حسنها مرتبط بالتصور الكلي المعتمد الذي يعطي الأفعال معانيها والأشياء دلالتها، وهو كذلك حكم مرتبط بفهم معاني الوحي ودلالاته. ولأن القِيَم الموجهة للأفعال، تنبثق عن التصور العام والرؤية الكلية للوجود، فإن العقل لا يستطيع أن يحكم على حسن الفعل أو قبحه إلا إذا ربط القِيَم الأخلاقية بمصادرها الوجودية. وبالمثل أخطأ الجويني عندما جرّد العقل من أي قدرة على تمييز الحسن من القبيح بعيداً عن الوحي. إذ يستحيل على المرء الانجذاب إلى الحسن والنفور من القبح ما لم يكن الحسن والقبح مرتبطين بالبنى الذاتية للعقول ومتعلقين بطبائع الأمور. لذلك نبه القرآن الكريم إلى تعلق قبول الوحي

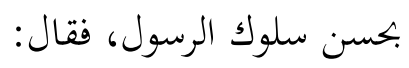

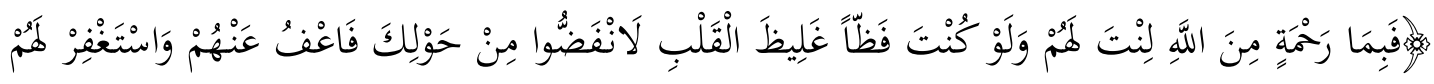

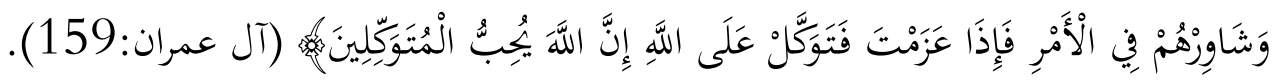

$$
33 \text { 32 } 33 \text { أبو المعالي الجويني: الإرشاد إلى قواطع الأدلة في أصول الاعتقاد، مصدر سابق، ص228. } 231 .
$$


كما أشار إلى التوافق بين الهدي الإلمي المنزل والتوجيهات القرآنية من جهة، والميول الفطرية التي جبل

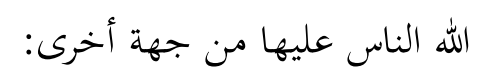

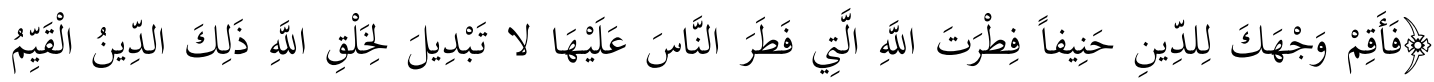

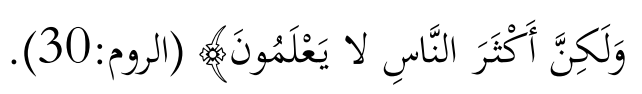

بناءً على ما سبق يمكن القول أنّ العقل البشري قادر، بما أودع الله تعالى فيه من إمكانيات، على تبين

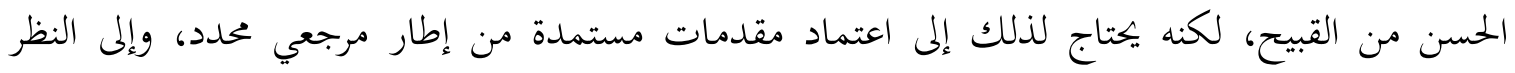

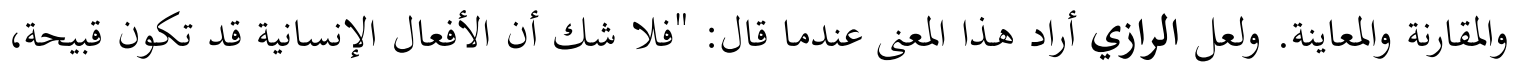
وذلك الحسن والقبح قد يكون العلم به حاصلاً من غير كسب، وقد يمتاج فيه إلى كسب فاكتسابه إنما يكون بقدمات تلائمها".

وكما تأثر الفلاسفة المسلمون بفكرة كفاية العقل لتحسين الأفعال وتقبيحها الإغريقية تأثروا أيضاً بقدرة العقل الذاتية على تحديد بنية الوجود بشقيه المحسوس والمغيب. فاستعار الفلاسفة المسلمون نظرية المستويات

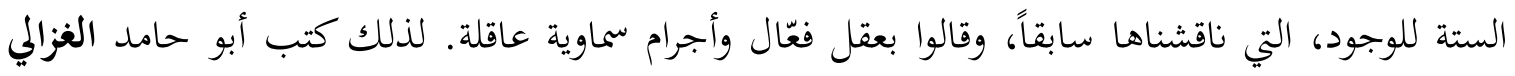
كتابه الشهير تحافت الفلاسفة ليظهر أن الفلاسفة يسيرون في أصقاع المعارف الغيية والماورائية بلا دليل، "وأخم يمكمون بظن وتخمين، ومن غير تحقيق ويقين". 36

وييين الغزالي بطلان كثير من البراهين التي قدّموها لإثبات مواقفهم. فعند الحديث عن الأطروحة التي

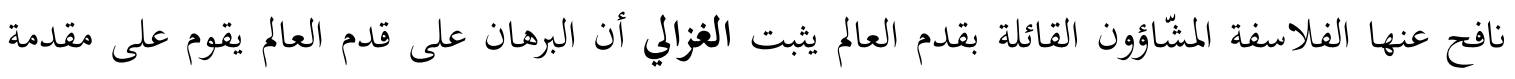
فحواها "استحالة صدور حادث عن إرادة قديمة،" وأن هذه المقدمة ظنية لا بككن التيقن من صدقها. فهي

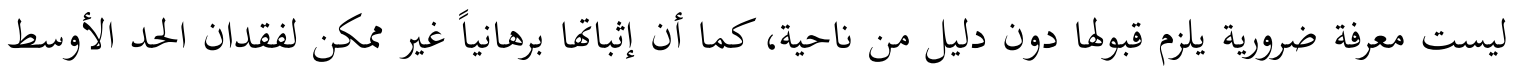

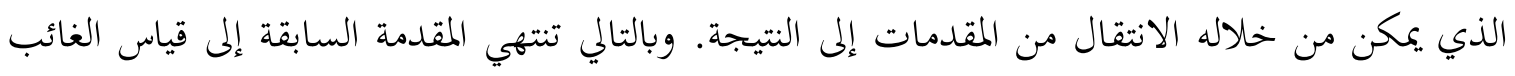
على الشاهد، وهو قياس غير صحيح لانعدام التشابه بين طري القياس. فلا يمكن قياس الذات الإلهية

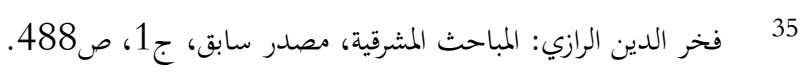

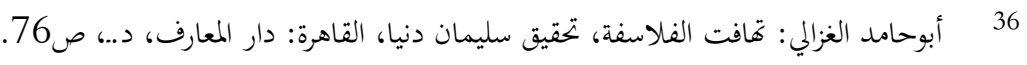


المطلقة على الذات الإنسية المحدودة. 37 فإذا نظرنا في برهان الفلاسفة على قدم العالم وجدنا أنه يتألف من ثلاث قضايا رئيسية:

$$
\text { 1 - 1 العالم صادر عن الله. }
$$

2- الله قديم، فإرادته وقدرته قديمتان.

$$
\text { 3- العالم قديم، لامتناع صدور الحادث عن إرادة وقدرة قديمتين. }
$$

فاعتراض الغزالي على المحاكمة السابقة يتحدد في أن النتيجة (3) ليست صادرة عن برهان يتألف من مقدمة صغرى ومقدمة كبرى يجمعهما حد أوسط، كما أها ليست بيّنة بذاتما ليُشتغنى عن البرهنة عليها. لذلك فإن استبدالها بنتيجة مقابلة لها ممكن، وعند ذلك تصاغ النتيجة على النحو الآتي: العالم حُحَْث، لإمكان صدور المحدث عن إرادة وقدرة قديمتين.

وهكذا أظهر الغزالي عجز العقل البشري عن تحديد الحقائق الغيبية الماورائية من خلال مقدمات نظرية، وحاجته بالتالي إلى مقدمات مستمدة من الخبرة الحسية أو معرفة منبثقة من عبارات الوحي المنزّل. وهذا ما دفع ابن رشد إلى التصدي للنهج الكلامي الذي يستعيد مقدمات خصومه النظرية لإتبات آرائه العقدية، والدعوة إلى الانطلاق من مقدمات الوحي عند البحث في المسائل الغيبية. لذلك يَحْمل ابن رشد في كتابه تقافت التهافت على المتكلمين أغم اعتمدوا مقدمات نظرية برهانية في إثبات حدوث العالم من عدم، ضاربين الصفح عن الشاهد في الخبرة الحسية والوحي الإلهي لا يساند موقفهم هذا. فالحبرة الحسية تظهر لنا أن الأشياء المادية صادرة عن أشياء مادية سابقة لها، وآيات الكتاب تظهر أن خلق السموات والأرض والإنسان لم يكصل من عدم، بل صدر عن عناصر متقدمة عليهم: 12:12). 


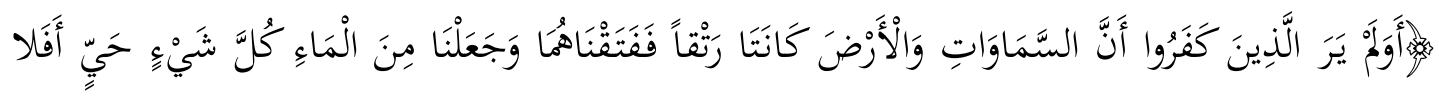

$$
\text { يُوْْمِنُونَ (الأنبياء:30). }
$$

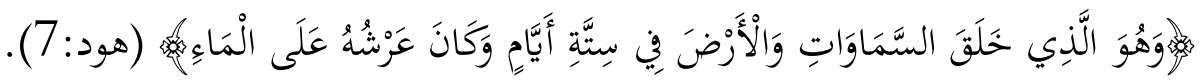

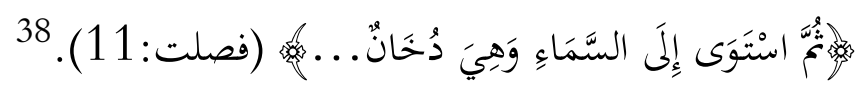

لذلك يدعو ابن رشد في كتابه "فصل المقال وتقرير ما بين الشريعة والمكمة من اتصال" إلى منهج

بديل يقوم على اعتماد المقدمات القرآنية عند النظر في الغيبيات. وييين ابن رشد منهجه هذا بقوله: "فإن قيل فإذا لم تكن هذه الطرق التي سلكها الأشعرية وغيرهم من أهل النظر هي الطرق المشتركة التي قصد

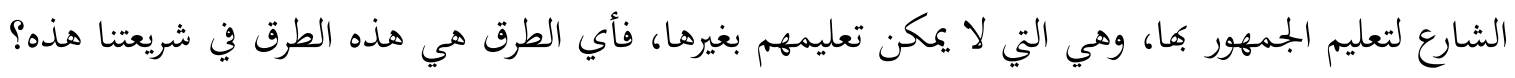

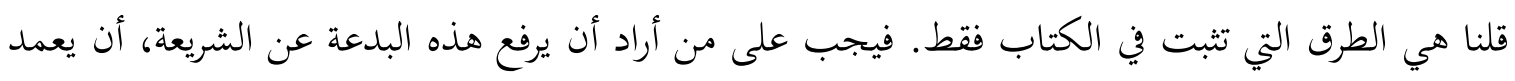

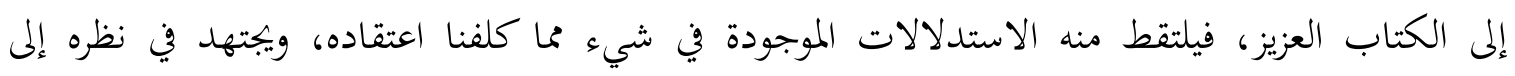
ظاهرها ما أمكنه من غير أن يتأول من ذلك شيئاً، إلا إذا كان التأول ظاهراً بنفسه، أعني ظهوراً مشتركاً للجميع".

لكن دعوة ابن رشد إلى استبدال مقدمات نظرية بمقدمات مستمدة من القرآن في الغيبيات لا يؤدي

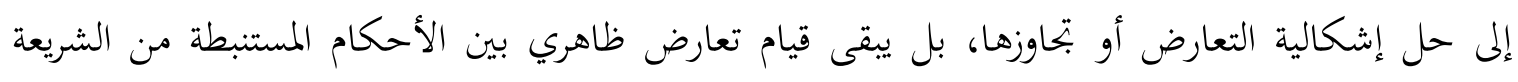

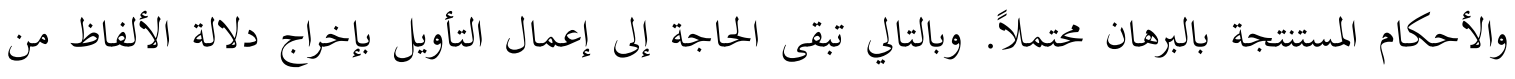

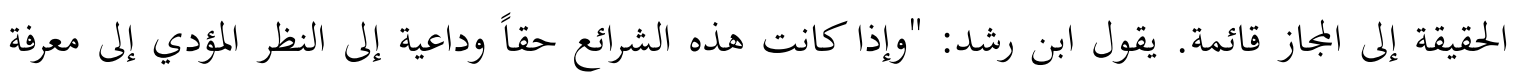

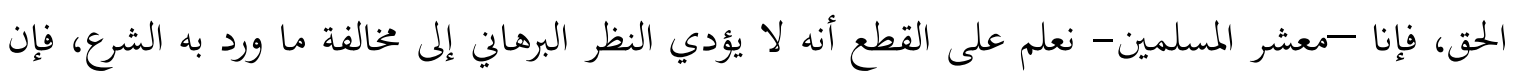

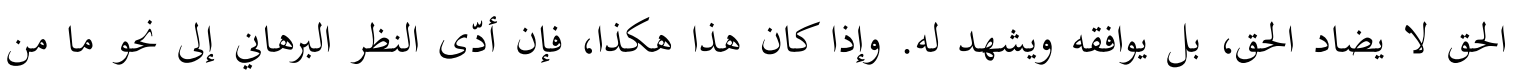

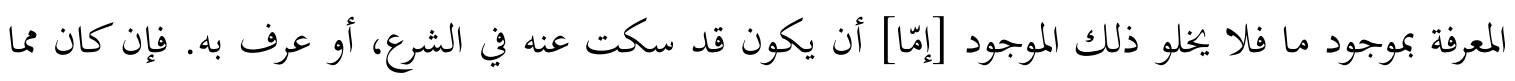

$$
\begin{aligned}
& 38 \text { 38 } 38
\end{aligned}
$$

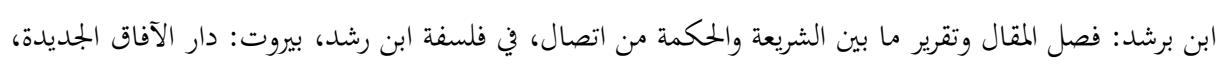


سكت عنه، فلا تعارض هنالك، وهو بمنزلة ما سكت عنه من الأحكام فاستبطها الفقيه بالقياس الشرعي. وإن كانت الشريعة نطقت به، فلا يخلو ظاهر النطق [إمّا] أنْ يكون موافقاً لما أدّى إليه البرهان فيه أو مخالفاً. فإن كان موافقاً فلا قول هنالك وأن كان مخالفاً طلب هنالك تأويله. ومعنى التأويل، هو إخراج دلالة اللفظ من الدلالة الحقيقية إلى الدلالة المجازية، من غير أن يخل في ذلك بعادة لسان العرب في التجوّز من تسمية الشيء بشبيهه، أو سببه أو لاحقه أو مقارنه، أو غير ذلك من الأشياء التي عددت في تعريف أصناف

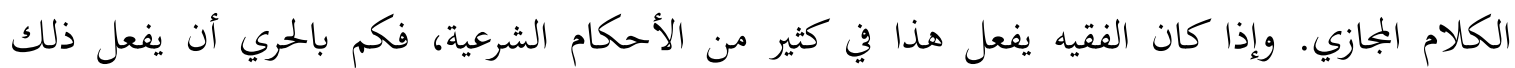
صاحب العلم بالبرهان. فإن الفقيه، إنما عنده قياس ظني، والعارف عنده قياس يقيني. ونخن نقطع قطعاً أن كل ما أدى إليه البرهان وخالفه ظاهر الشرع، أن ذلك الظاهر يقبل التأويل على قانون التأويل العربي، وهذه القضية لا تشك فيها مسلم، ولا يرتاب بها مؤمن. وما أعظم ازدياد اليقين بها عند من زاول هذا المعنى وجربه، وقصد هذا المقصد من الجمع بين المعقول والمنقول". 40 وهكذا نجد أنفسنا ثانية وجهاً لوجه مع إشكالية التعارض عند ابن رشد الذي حرص على تجنب مزالق المتكلمين ولكنه لم يتمكن من اجتناب الإشكالية التي شغلتهم وأدت إلى انقسامهم إلى معتزلة وأشاعرة.

لقد استطاع الفكر الإسلامي في مرحلة نضجه في القرنين الخامس والسادس الهجريين تطوير تصور دقيق لبينة العقل وتحصيل فهم عميق لآليات التفكير، ولكنه بقي مع ذلك عاجزاً عن بحاوز إشكالية التعارض التي برزت بصورتا المتكاملة في كتاب ابن تيمية درء تعارض العقل والنقل. لذلك فإننا في المبحث الآتي نلقي مزيداً من الضوء على هذه الإشكالية، ونحاول الإجابة عن سؤال سابق على السؤال الذي طرحه

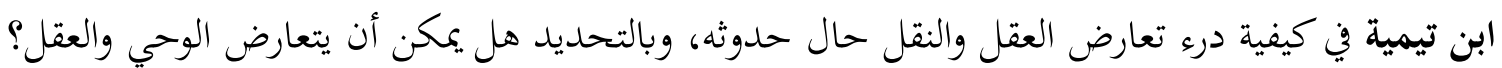

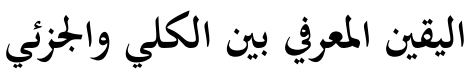

إن الحديث عن التعارض بين الوحي والعقل يفترض قيام علاقة تشابه أو تماثل في المحتوى والمضمون. فنحن مثلاً لا نتحدث عن تعارض بين مفاهيم وقضايا الجغرافيا والكيمياء، نظراً لاختلاف طرائق النظر وموضوعه في كل من الدائرتين المعرفيتين السابقتين. فالحكم الجغرافي بأن "جبال الهملايا أعلى جبال في العالم" 
لا يتعارض مع الحكم الكيميائي بأن "المعادن تذوب في الحوامض". فهل يتماثل مضمون الوحي ومضمون

ينقسم العقل، كما رأينا، إلى قسمين: قسم فطري أو غريزي وآخر متحصل أو مكتسب. فإذا نظرنا في البنية الداخلية لكل من هذين القسمين وجدنا أن العقل الفطري يتحدد بالقدرة على توليد تصورات كلية بسيطة تتحصل من خلال تجريد المدركات الحسية، ترتبط فيما بينها لتشكل أحكاماً أو تصديقات ينجم عنها تصورات مركبة. كما يتألف العقل الفكري من مجموعة أحكام شكلية أو صورية تشكل القواعد المنطقية والرياضية، مثل قاعدة الوسط المرفوع وعدم الثناقض وكون الكل أكبر من أيّ من أجزائه. وهذا القسم من العقل هو الذي يمثل القاسم المشترك بين الناس كلهم، ويؤدي فقدانه إلى اختلاف الفهم والعجز عن التفكير السليم. أما القسم الآخر من العقل، العقل المكتسب، فإنه متحصل من الخبرة الإنسانية، ومتولد من تطبيق العقل الفطري على موضوع ما. فعملية النمو العقلي في حقيقتها نمو للعقل المكتسب بتحصيل المعارف إما بالتعلم والاستفادة من خبرات السابقين أو بتطبيق مبادئ العقل الفطري على مصدر معرفي معين. فإذا نظرنا في محتوى العقل المكتسب وجدنا أنه ينطوي على تصورات وتصديقات (أو مفاهيم وأحكام) تنقسم إلى أنواع ثلاثة متمايزة: - n

1- أحكام متعالية عن الوجود الحسي ومرتبطة بالوجود المغيّب، كالحكم بأن النفوس تبعث من جديد بعد موتا لتثاب على أعمالها. 2- أحكام قيمية توجه العقل البشري في دائرة الحياة الاجتماعية، كالحكم بأن الصدق حسن والكذب

3- أحكام تجريبية مستمدة من ملاحظات الإنسان الطبيعية والتاريخية، كالحكم بسقوط الأجسام التي تزيد كثافتها عن كثافة الهواء نحو مركز الأرض، أو الحكم باقتضاء الفساد الإداري في مجتمع ما تراجع اقتصاده واهيار حضارته وعمرانه. 
إن التأمل في بينة العقل يظهر لنا أن التعارض بين أحكام الوحي وأحكام العقل الفطري غير ممكن، نظراً لخلو العقل الفطري من الأحكام المضمونية واقتصاره على الأحكام الإجرائية. فالعقل الفطري ذو الطبيعة الإجرائية لا يملك أن يقضي بصدق أحكام مضمونية منفردة أو بكذها، لكنه قادر على الطعن في مصداقية منظومة من الأحكام من خلال إظهار تناقضها الداخلي. فلا يملك العقل الفطري مثلاً أن يعارض حكم القرآن بخلق الإنسان من طين، أو حكمه بمسؤولية الإنسان أمام الله في يوم يبعث فيه بعد موته، ولكنه يملك أن ينظر في اتساق الحكم الأول مع الثاني. فإذا ظهر الاتساق الداخلي لمنظومة الأحكام القرآنية امتنع على العقل الفطري الاعتراض أو التشكيك في أي حكم منفرد من أحكام القرآن.

فإذا امتنع قيام تعارض بين الوحي والعقل الفطري، هل يمكن قيام تعارض بين الوحي والعقل المكتسب؟ للإجابة عن هذا السؤال يجدر بنا أن نلحظ بدءاً البنية الداخلية للخطاب القرآي. إذ يتألف القرآن من آيات تنطوي على أحكام متعلقة بثلاثة مستويات من الوجود: الوجود الكلي المغيّب، والوجود الطبيعي المشاهد، والوجود الإنساني المعيش، لكن الأحكام القرآنية هذه ليست أحكاماً ناجزة، بل أحكاماً ثاوية في النص المنزل تحتاج إلى إعمال عقل ونظر قبل استخراجها. ولأن الوحي مصدر معريز يستمد العقل مضمونه منه فإن قيام تعارض مباشر بين آيات الكتاب والعقل المكتسب من تطبيق العقل الفطري على تلك الآيات متنع أيضاً. إذ لا يمكن بأي حال أن تتعارض المفاهيم والتصورات المستمدة من مصدر معريف مع المعطيات المعرفية لذلك المصدر لأن تلك المعطيات تؤلف المادة التي يستخدمها العقل الفطري لتشكيل العقل المكتسب. فمصدر التعارض بين العقل والوحي لا بد أن يعود إلى أحكام ناجمة عن مصادر أخرى.

$$
\text { فما هي المصادر الأخرى المولدة للمعارف العقلية؟ }
$$

المصدر الآخر للمعرفة الذي تتولد منه تصورات العقل وأحكامه هو الوجود الطبيعي والاجتماعي للإنسان. لقد ارتبط مفهوم العقل بالمعرفة الطبيعية ارتباطاً حميماً حتى أطلق المسلمون المتقدمون صفة "عقلي" على كل ما ارتبط بالنظر في المحيط الطبيعي والاجتماعي للإنسان. لذلك أدرج علماء المسلمين القدماء في لافتة العلوم العقلية علمَ الطب والهندسة والحساب والفلك والسياسات المدنية. فانقسام العلوم بين عقلي ونقلي يكشف لنا بعداً جديداً في طبيعة إشكالية التعارض يتعلق بالمعارف المكتسبة من خلال النظر في 
معطيات الواقع المحسوس، والتأمل في بنية الواقع المشهود. ومن هنا يظهر لنا أن مشكلة تعارض العقل والنقل لا تنبع من رفض عقلي مباشر لنصوص منقولة، بل تتعلق بتناقض دلالات النص المنقول وبتليات الواقع المشهود. لكننا إذا أنعمنا النظر في طبيعة الأحكام المضمونية المستمدة من الوحي والواقع وجدنا أن التعارض بين العقل المكتسب والوحي القرآي متتنع في دائرة الأحكام المتعالية والقيمية لأن النظر في الواقع المشهود لا يمكن أن يولد أحكاماً متعالية أو قيمية دون هداية الوحي ذاته، الذي يمثل المصدر الرئيسي لمثل هذه الأحكام. فإمكان التعارض قائم في دائرة الأحكام التجريبية وحدها.

بيد أنه من الطريف ملاحظة أن هذه الدائرة لم تكن يوماً من الأيام، عبر تاريخ الفكر الإسلامي كله مداراً للتعارض. بل إن كثيراً ممن يتحفظ على إعمال "العقل" في النص من المفكرين المعاصرين يجد في العلوم الفلكية والطبية والجغرافية المعاصرة مُعيناً على إظهار صدق النص المنزل وإعجاز القرآن، بدءاً من تخلُق الجنين وأطواره، مروراً بحركات الأفلاك وأبعاد النجوم، وانتهاءً ببنية جسم الإنسان. في حين أن الخلافات التصورية بين فرق المسلمين ومذاهبهم تركزت في دائرة الأحكام المتعالية. لذلك فإننا نرى أن إشكالية التعارض في جوهرها ليست تعارضاً بين أحكام، لامتناع قيام أي تعارض بين الأحكام المستمدة من الوحي المقطوع في ثبوته وتلك المستخرجة من النظر في آيات الآفاق والأنفس. بل التعارض في حقيقته تعارض بين منهجيات في البحث والنظر، ومنظومات الأحكام المضمونية الناجمة عنها. لذلك وجدنا أن الخلاف بين ابن تيمية والرازي، أو بين ابن رشد والفزالي، ليس خلافاً في تعارض أحكام نقلية وعقلية بعينها، بل خلاف في آليات الاستدلال ومصادره. فعلى الرغم من تقرير عالم جليل كابن تيمية لمبدأ تقديم القطعي على الظني تراه يتردد في تقديم قطعيات العقول على ظنيات الأخبار، ويلجأ لذلك إلى التشكيك في أولويتها وترجيح بطلانما بدعوى أن "مقدمات الأدلة العقلية المخالفة للسمع فيها من التطويل والخفاء والاشتباه والاختلاف والاضطراب ما يوجب أن يكون تطرق الفساد إليها أعظم من تطرقه إلى مقدمات الأدلة السمعية". 41 فالقضية في جوهرها إذن قضية رفض لتحكيم العقل في النص، سواء ما تعلق منه بتأويل آيات الكتاب عند امتناع حمل معانيها على ظاهرها أو بردّ أخبار الآحاد ظنية الثبوت عند تعارض متنها مع اليقينيات العقلية.

41 ابن تيمية: درء تعارض العقل والنقل، مصدر سابق، ص174. 
بيد أن الموقف الرافض لإقحام العقل في فهم النص، والمصر على الحرفية في الفهم والاتباع حتى عندما تتعارض دلالة النص الظاهرية مع ما اعتقده العقل يقيناً، موقف مضطرب يؤدي في النهاية إلى اعتبار الجزئي ورفض الكلي، واعتماد الظني ورد اليقيني. ذلك أن فهم النصوص وتحديد دلالاتها يتوقف على أمرين؛ الأول تحديد معاني الألفاظ من خلال مقارنتها بالاستخدامات المختلفة للألفاظ ضمن الخطاب الكلي، وبالتالي فإن تحديد معنى الألفاظ المتضمنة في النص يجتاج إلى عملية استقراء ينتقل فيها العقل من الجزئي إلى الكلي، من خلال مقايسة الجزئيات بعضها ببعض. أما الأمر الثاني المهم الذي يتوقف عليه فهم النصوص فيتعلق باختيار المدلول وتحديد أوجه دلالة النص عليه. وهذا يعني أن فهم أي جزئي لا يتم إلا من خلال ربطه بمجموعة من الكليات التي تشكل في جوهرها الأحكام المضمونية لعقل المفسر لمفهوم النص. ومن هنا يظهر لنا أن القاعدة الكلية لدفع التعارض التي اعتمدها الغزالي في رسالة قانون التأويل، 42 وتابعه فيها ابن رشد في رسالة فصل المقال، 43 والرازي في أساس التقديس، 44 هي في حقيقتها دعوة إلى النظر في النصوص من خلال المبادئ والقواعد الكلية اليقينية التي تشكلت في عقل العالم نتيجة نظرة في نصوص الوحي ودلالاته الواقعية.

وبناءً على ما تقدم نخلص إلى أن الوصول إلى اليقين المعريف لا يمكن أن يتم إلاّ من خلال تطوير منظومة من الأحكام الكلية اليقينية المتحصلة من خلال نظر واستدلال عقليين في مصدري المعرفة الرئيسيين: الوحي والواقع. بمعنى أن الأحكام الكيلة هذه تتولد نتيجة لتواطؤ الأحكام الجزئية المستقرأة من مفردات الوحي وتجليات الواقع. ومن هذا المنطلق يظهر تَافت الدعوة إلى تأسيس المواقف على أساس نصوص مجتزئة أو حوادث متفرقة. ذلك أن تضافر النصوص وتواطؤ الحوادث شرط أساسي للوصول إلى قناعات راسخة وأحكام راجحة، ومن ثيّّ تأسيس تصور كلّي لمجال من مجالات الوجود. وهكذا يظهر لنا أن تعارض العقل والنقل في فحواه تعارض بين نصوص جزئية وبمموعة من المبادئ الكلية. وبالتالي فإن النظر العلمي يقتضي إلحاق الجزئي بقاعدة كلية، فإن تعذر نظرنا في إمكان تعديل

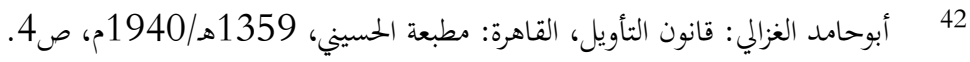

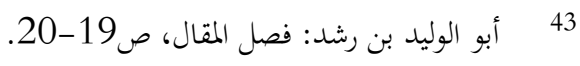

$$
\begin{aligned}
& 44 \text { فخر الدين الرازي: أساس التقديس، بيروت: دار الفكر اللبناني، 1993م، ص125-126. }
\end{aligned}
$$


القاعدة الكلية لدفع التعارض بين الكلي والجزئي، فإن تعذر فلا مفر من التوقف في اعتبار الجزئي واستمرار العمل بالكلي، أي التوقف في النص واعتماد منظومة القواعد الكلية التي تشكل البنية الداخلية لعقل الناظر

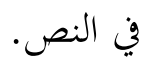

ولمعترض أن يقول: إن تحويل إشكالية التعارض إلى علاقة بين جزئي نقلي يعاد تأويله في مقابل كلي عقلي، أو كلي عقلي يعمد إلى تعديله للإحاطة بجزئي نقلي تفترض أن العقل الناظر تشكل بتأثير دلالات الوحي، وبمعزل عن أي تأثيرات أخرى قد تؤدي إلى تشويه الفهوم والتصورات. والحق أن هذا الاعتراض لا لا بـ يمكن إهماله أو بتحاهله، خاصة وأن العديد من كبار رجالات الفكر الإسلامي، كالجويني، والغزالي، وابن رشد، قد خضعوا لتأثيرات فكرية إغريقية مخالفة في رؤها الكلية للرؤية الكلية الإسلامية. بيد أن هذا الاعتراض لا ينفي أهمية المنهجية التي نبهنا إليها، ولكنه يبيّن ضرورة الممارسة النقدية المستمرة للتصورات والتصديقات التي تئلف محتوى العقل. إذ أن البديل لإعمال العقل في النص وفي الواقع ليس إلاّ استقالة العقل وجمود الفكر، والانعزال في فراغ نظري منفك عن الواقع الحميط وعاجز عن فهمه والتأثير فيه.

\section{تكامل الوحي والعقل}

خلق الله تعالى الإنسان وميزه من سائر مخلوقاته بعقل مريد، واستعمره كوناً فسيحاً منتظماً وفق نظام دقيق، ومكن الإنسان بما أودعه من قدرات عقلية من استقراء القواعد الكلية التي تحكم نظام الطبيعة. وخاطبه بخطاب بليغ ذي دلالات عميقة وأعانه على فهمه بما زوده من قدرات ذهنية. فالعقل الإنساني مدار التكليف ومدار فهم معاني الخطاب ومبادئ النظام. ومن خلال تفاعل العقل الإنساني مع دلالات الوحي وتجليات الواقع نشأت العلوم وتطورت، وتوارثتها الأجيال. فتكاثفت النظريات وتعددت التفسيرات وتضاربت الآراء واختلفت النقول، ولا سبيل لتمبيز الحق من الباطل وتبين الخطأ من الصواب إلا بإعمال الفكر والنظر المنهجي المطرد.

ولقد رأينا في الصفحات السابقة أن العلاقة بين الوحي والعقل علاقة معقدة متراكبة لا علاقة مباشرة بسيطة. فالعلاقة بادئ ذي بدء ليست علاقة ثنائية بل ثلاثية الأبعاد، تشمل الوحي والعقل والواقع. ثم إن كل ركن من أركان هذه العلاقة متعدد الأبعاد والمعاني. فالوحي يتألف من نصوص قرآنية، قطعية في ثبوتا، 
لكنها تحتمل القطع والظن في دلالتها، كما يتألف من نصوص حديثة، تنقسم إلى أحاديث آحاد ظنية الثبوت، وتمثل مجمل نصوص الحديث، وإلى أحاديث متواترة قطعية الثبوت. بينما يتألف العقل من أحكام فطرية وأخرى مكتسبة. أما الواقع فيتألف من الوجود العلوي المغيَّب والوجود الاجتماعي والوجود الطبيعي. لذلك فإننا نرى أن تجاوز هذه الإشكالية لا يمكن أن يتم من خلال قاعدة كلية، كتلك التي تقدم بها الغزالي والرازي، بل يحتاج إلى النظر في منهجيات التفكير والطرائق التي يتبعها العقل في جهده لتفسير النص وفهم الواقع. لكننا نستطيع من خلال استعراض ملابسات إشكالية تعارض العقل والنقل في تاريخ الفكر الإسلامي الخلوص إلى أن التعارض بين العقل والنقل في فحواه وحقيقته تعارض بين عقلين، أو بين منظومتين من الأحكام تم تطويرهما انطلاقاً من منهجيتين معرفيتين مختلفتين، واعتماداً على بنيتي معرفيين متغايرتين. ولتوضيح هذه النقطة لا بأس من العودة لاستعراض جذور الخلاف بين طريقة المحدّثين في التعامل مع المتشاجهات من النصوص، التي يمثلها ابن تيمية، وطريقة المتكلمين التي يمثلها الرازي. فقد كتب ابن تيميه كتابه درء تعارض العقل والنقل لتفنيد "القانون الكلي" الذي وضعه المتكلمون لتأويل المتشاهات، والذي اعتمده الرازي في كتاب أساس التقديس. وكان الرازي قد كتب كتابه هذا لإظهار اضطراب موقف "الحشوية" الذين يمنعون تأويل النصوص ومملها على المجاز، وللرد على ما ساقه محمد بن إسحاق بن خزيمة (توفي 311ه)، في كتابه التوحيد وإثبات صفات الرب، من نصوص تثبت لله صفاتٍ تجسيمية وتحدد له حيزاً وجهة. لذلك نرى الرازي ينبري إلى تنزيه الله تبارك وتعالى عن كل شبهة بتسيم أو تشبيه، فيمنع حمل ألفاظ اليد والرجل والوجه والرؤية والفوقية، وغيرها من الألفاظ التي تحتمل معنى التجسيم والتحيز، على الحقيقة ويلجأ إلى تأويل النصوص وحمل الألفاظ على المجاز.

إننا إذا تأملنا بإمعان في الأساس المرجعي الذي انبنى عليه موقف الرازي المنزّه لله تبارك وتعالى عن كل مظاهر التجسم والتحيز، والرافض لحمل الألفاظ التجسيمية على الحقيقة، وجدنا الأساس المرجعي متحدد بعدد من القواعد العامة والمبادئ الكلية التي استنبطت من نصوص الكتاب الكريم، وعضدت بعدد آخر من القواعد والمبادئ المستخرجة من طبائع الأشياء وخصائص الزمان والمكان. لذلك نراه في مطلع كتابه يسوق تسع عشرة "حجة" أو "دليلاً سمعياً"، استخرج ثماني عشرة منها من القرآن الكريم، ويعتمدها أساساً مرجعياً لتحديد دلالات النصوص الأخرى الواردة في هذا الموضوع. 
وبعبارة أخرى يمكننا القول أنّ الدلائل النصية المستخرجة من كتاب الله الحكيم تشكل ركناً رئيسياً للإطار المرجعي، أو منظومة الأحكام، التي يعتمدها الرازي لتحديد تصوره الكلي للوجود العلوي، والتي يستخدمها لتفسير النصوص الأخرى ذات الصلة أو تأويلها. وعلى الرغم من أن الرازي لم يعمد إلى تحديد القواعد النصية المشكّلة لإطاره المرجعي تحديداً منهجياً، فإنه من المفيد أن نعمد هنا إلى استخراج تلك تلك القواعد المستنبطة في محاكماته والثاوية في خطابه، والمتجلية عبر براهينه واستدلالاته. فباستعراض حجج الرازي نستطيع تمييز أربع قواعد تنزيهية:

$$
\begin{aligned}
& \text { القاعدة الأولى: يمتنع تشابه الباري أو تماثله مع أي من خلقه: } \\
& \text { 22 22). }
\end{aligned}
$$

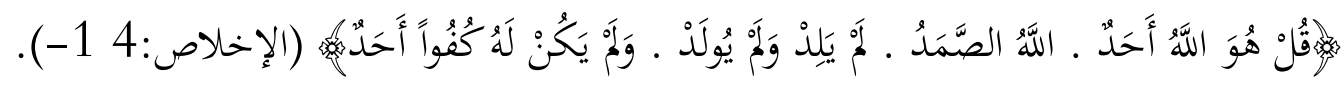

$$
\begin{aligned}
& \text { 111 11). }
\end{aligned}
$$

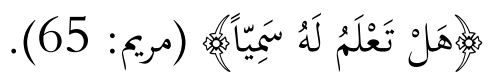

القاعدة الثانية: يمتنع تحيز الباري في سماء أو أرض لأنه خالق لمما، قيوم عليهما، ومستغن عنهما:

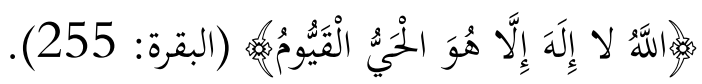

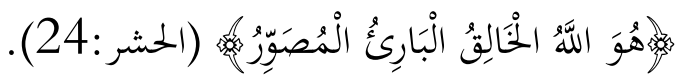

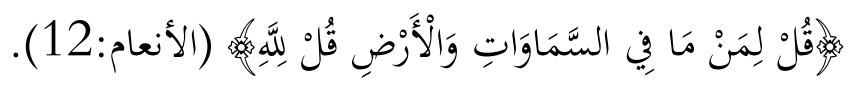

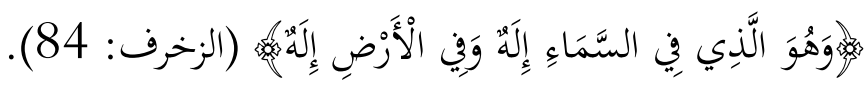

$$
\begin{aligned}
& \text { القاعدة الثالثة: يتسامى الباري عن حدود الزمان والمكان: }
\end{aligned}
$$

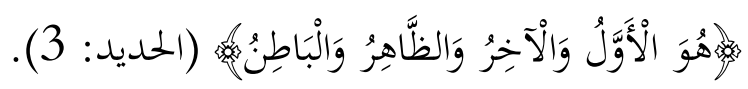




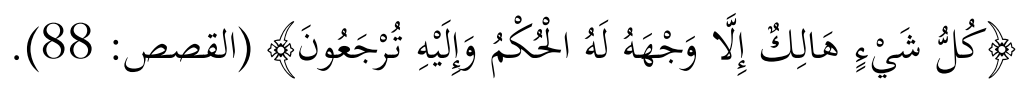

القاعدة الرابعة: يستحيل تخصص الباري في جهة:

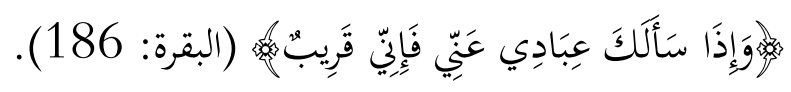

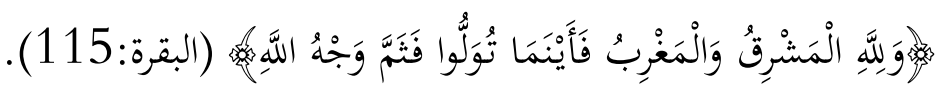

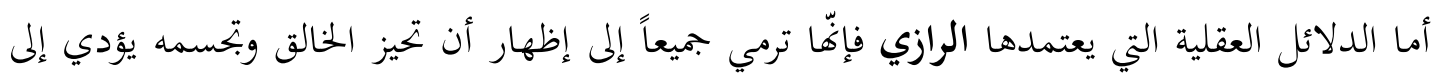

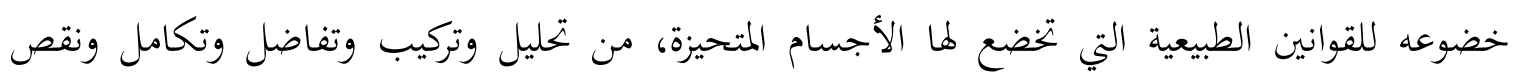
وزيادة، وبالتالي إلى نفي خصائص الكمال والتنزه المرتبطة بحقيقة الألوهية.

ومن ناحية أخرى ينبه الرازي إلى خطأ اللجوء إلى قياس الغائب على الشاهد عند البحث في صفات الله تعالى وعلاقته بالكون والوجود الإنساني. ذلك أن قياس الغائب على الشاهد يفترض تماثل المقيس عليه

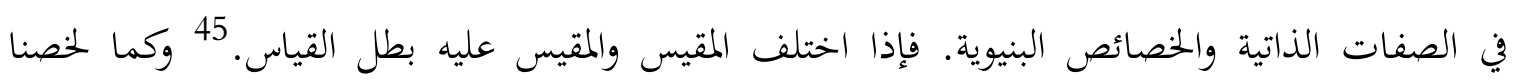
حجج الرازي النصية في قواعد أربع، يككنا تلخيص حججه العقلية في قاعدة كلية واحدة، تنضاف إلى لئل

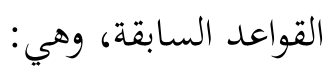

القاعدة الخامسة: يكتع قياس الغائب على الشاهد عند تحديد صفات الذات الإلهية لاختلاف المقيس والمقيس عليه.

وبذلك تكتمل القواعد الكلية التي تشكل منظومة الأحكام التي يرجع إليها الرازي لدى تأويله للنصوص وتحديده لدلالات الألفاظ المرتبطة بأسماء الله وصفاته.

وانطالاً من منظومة الأحكام السابقة يعمد الرازي إلى استعراض النصوص التي يدل ظاهرها على

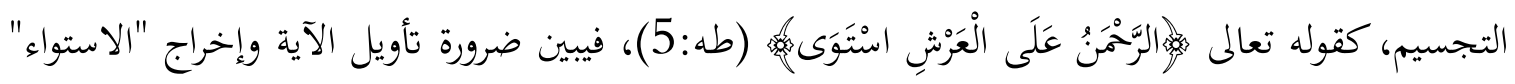
من الحقيقة إلى البماز لاستحالة حمل المعنى على الحقيقة. فحقيقة الاستواء الاستقرار على العرش والجلوس

$$
\text { 45 الرازي: أساس التقديس، مصدر سابق، ص63. }
$$


عليه، وهو محال في حق الله تبارك وتعالى. ويخلص الرازي إلى أن الاستواء يعني، في سياق الآية، الاستيلاء والقهر والسيطرة: "إن الدلائل العقلية التي قدمنا ذكرها تبطل كونه تعالى مختصاً بشيء من الجهات. وإذا ثبت هذا ظهر أنه ليس المراد من الاستواء الاستقرار، فوجب أن يكون المراد هو الاستيلاء والقهر ونفاذ القَدَر، وجريان الأحكام الإلهية".

إن الاختلاف بين المتكلمين والمحدّثين، الذي أثار إشكالية تعارض العقل والنقل، ودفع الرازي إلى الردّ على"حشوية" ابن خزيمة، ودفع ابن تيمية إلى التصدي "لعقلانية" الرازي، في حقيقته اختلاف منهجي أدى إلى اختلاف في منظومة الأحكام التي تشكل الإطار المرجعي للحكم على الأشياء والأوضاع والأحداث، والتي توجه عملية الفهم والتفسير والتأويل. لذلك نجد الرازي في ختام كتابه يحمل بشدة على المحدِّثين الذين ينهون عن اعتماد "العقل" لتأويل متشابه الكتاب، اعتقاداً منهم أن إعمال العقل في النص يؤدي إلى تفسير القرآن الكريم وفق فهوم بشرية ظنية محدودة، بينما بحدهم يلجؤون إلى أحاديث آحاد مظنونة تعطي تفسيرات تتصادم مع نصوص القرآن القطعية: "والعجب من الحشوية أفم يقولون: الاشتغال بتأويل الآيات المتشاهة غير جائز، لأن تعيين ذلك التأويل مظنون. والقول بالظن في القرآن لا يجوز. ثم إغم يتكلمون في ذات الله تعالى وصفاته بأخبار الآحاد، مع أها في غاية البعد عن القطع واليقين. إذا لم يجمّزا تفسير ألفاظ القرآن بالطريق المظنون، فلأن يمتنعوا عن الكلام في ذات الحق تعالى وفي صفاته بمجرد الروايات الضعيفة أولى". 47 إن القضية التي يثيرها الرازي هنا قضية منهج استنباط المفاهيم والأحكام من النصوص. فنراه يرفض منهج المحدثين الذين يعتمدون الأخبار المرفوعة إلى رسول الله صلى الله عليه وسلم طالما صح سندها، ولا يرون حاجة في النظر إلى الاتساق الداخلي للمفاهيم والأحكام المستنبطة من أحاديث الآحاد، ذات الطبيعة الظنية، ولا يبدون رغبة في التحقق من انسجام المعاني المستخرجة من الحديث وتلك المستمدة من القرآن الكريم. ويأخذ على المحدثين ردهم روايات عند اضطراب سندها بسبب اشتهار أحد ناقليها بميل حزبي أو خلاف تصوري، وقبولمم روايات رغم اضطراب متنها نتيجة تناقض ما جاء فيها من وصف الله تعالى ومفهوم الألوهية: "إن هؤلاء المحدثين يُخرجون الروايات بأقل العلل، مثل: إنه [ناقل الرواية] كان مائلاً إلى حب علي،

$$
\text { 47 }
$$


فكان رافضياً، فلا تقبل روايته؛ ومثل: كان معبد الجهني قائلاً بالقدر، فلا تقبل روايته. وما كان فيهم عاقل يقول: إنه وصف الله تعالى بما يبطل إلهيته وربوبيته فلا تقبل روايته. إن هذا من العجائب". 48

إننا لم نقصد من إظهار طبيعة الحلافات التي أدت إلى إشكالية تعارض العقل والنقل الانتصار لموقف المتكلمين أو المحدثين في مسألة تأويل صفات الذات أو التوقف عند ظاهر الألفاظ. فنحن نميل إلى صرف الجهد في تأوّل نصوص الكتاب بالنظر إلى الكيفيات التي يمكن من خلالها إعادة الفاعلية للنص القرآني وربطه بالواقع العملي للمجتمع الإنساني، 49 بدلاً ن الاستغراق في النظر الغبي؛ وإن كنا نعتقد أن حداً أدنى من التأويل الذي يمنع تعطيل النصوص ومملها على معان بحسيمية ضروري. ${ }^{50}$ بل أردنا من عرضنا هذا إظهار أن ما أسماه المتقدمون "تعارض العقل والنقل: هو في أساسه وجوهره تعارض بين إطار مرجعي يتألف من منظومة من القواعد والأحكام استنبطها العقل من خلال النظر في آيات الكتاب وآيات الكون، ثم استبطنها في عملية تفسير النصوص وتأويل الألفاظ، وبين أحكام أحادية انبنت على نصوص مجتزئة.

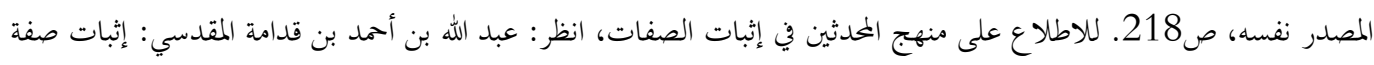
48

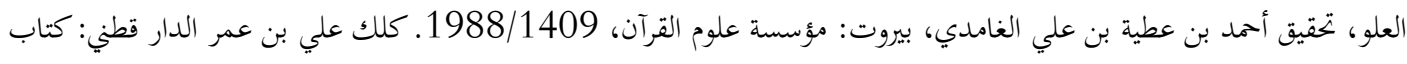

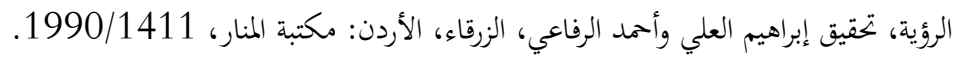

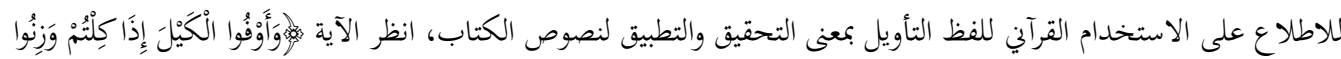

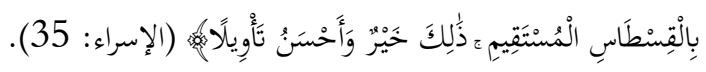

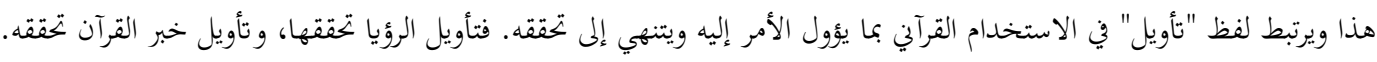

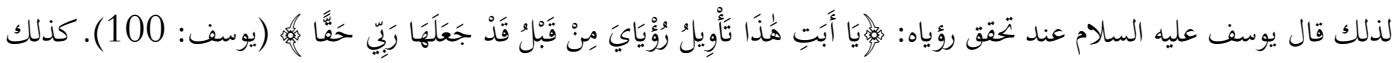

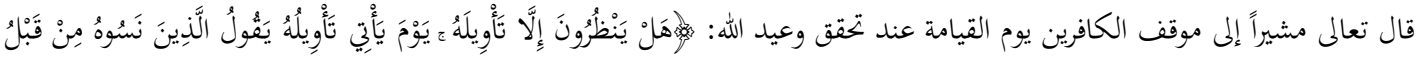

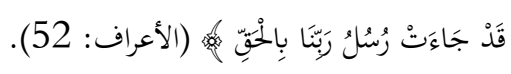

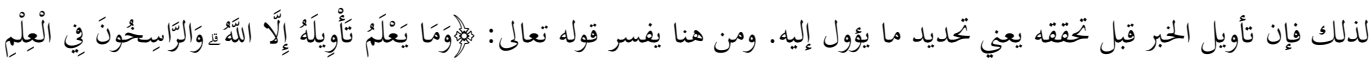

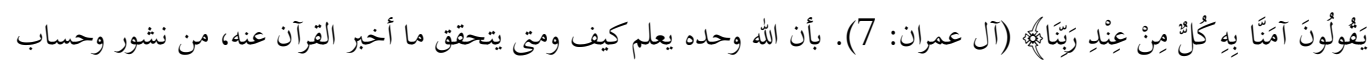

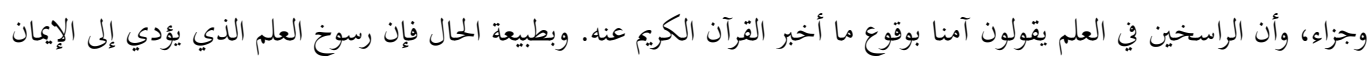

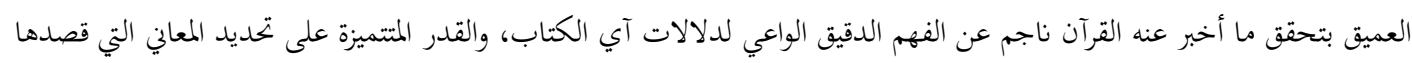
القرآن تحديداً مقارباً.. انظر مناقشة عميقة للموضوع في: التيجاني عبد القادر حامد: "التفسير التأويلي وعلم السياسة"، بجلة إسلامية المعرفة، العدد العاشر،

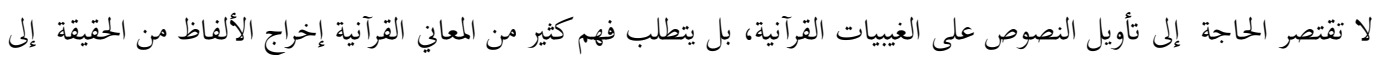
50

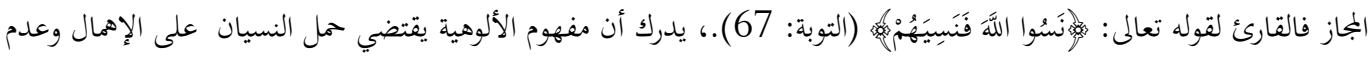


وكما نعلم فإن العقل التكاملي المعتمد على الرؤية القرآنية والحبرة الإنسانية العملية الذي استبطنته ثلة من كبار العلماء، والذي كان له أثر كبيرٌ في إرساء صرح الحضارة الإسلامية في القرنين الرابع والخامس الهجريين، لم يلبث أن تراجع واضمحل لأسباب كثيرة ليس ههنا المجال لبحثها، ليخلي مكانه لعقلية تراثية تقليدية ما زالت تيمن على العقول والأفكار. ولعل في مقدمة الأسباب التي أدت إلى تراجعه وذبوله، والتي بتعل مهمة استنهاضه عسيرة، عدم بتجلِّ العقل التكاملي في منهج علمي يبين مصادره وبنيته وأدوات استخراج عناصره. لذلك فإننا نرى أن مهمة تحديد المنهج التكاملي الذي انطوى عليه العقل التكاملي، ومن ثمَّ تطويره ليستوعب التطورات المعرفية التي طرأت خلال فترة غيابه الطويلة، مهمة أساسية من مهام الفكر الإسلامي المعاصر.

ولأن مهمة تحديد منهج متأمل تحتاج إلى دراسة مستفيضة، 51 فإننا نكتفي هنا باستخلاص عدد من المبادئ المنظمة للعلاقة بين الوحي والعقل والوجود انطلاقاً من الرؤى والتصورات التي توصلنا إليها في بحثنا

أولاً: يتعلق مفهوم العقل ابتداءً، بآليات الفهم ومبادئ التفكير السليم، وبالتالي يرتبط عمل العقل بتحديد منهج البحث وطرائق الاستدلال العلمي. وتتمثل وظيفة العقل في هذا المجال باستخراج المفاهيم والأحكام من المصدرين الرئيسيين للمعرفة: الوحي والواقع. فالعقل هنا يمثل معياراً لصواب الاستدلال أو خطئه. لكن مفهوم العقل يتسع بعد ذلك ليشمل الأحكام المضمونية المكتسبة نتيجة لتطبيق العقل الفطري على مصادر المعرفة الرئيسية. ذلك لأن المرء لا يلبث أن يستخدم الأحكام المضمونية للحكم على صواب المعطيات المعرفية المستجدة لديه وخطئها أو صدقها وكذبها.

بيد أن العقل لا يكتسب كل معارفه من خلال النظر الذاتي والخبرة الشخصية، بل يستبطن كمّاً هائلاً من المعارف المتوارثة عبر الأجيال والمتراكمة خلال الأزمان. وهذا ما يجعل التراث الفكري مصدراً معرفياً 
إضافياً. ولعل الكثير من التشوهات التصورية والزلات الفكرية ناجمة عن اعتماد فكر موروث دون إعمال لقدرات العقل النقدية، ودون النظر إلى الاختلافات في السياق الاجتماعي والتراكمات المعرفية.

ثانياً: يرجع تعارض الوحي والعقل في التحليل النهائي إلى تعارض بين منظومات متباينة من أحكام مضمونية تم استخراجها من مصادر معرفية مختلفة، واعتمد في توليدها منهجيات بحثية متغايرة. فالتعارض بين الوحي والعقل في دائرة المعارف الغيبية أو القيمية قد يتولد، مثلاً، عن اعتماد أساليب متغايرة في التفسير، أو اعتبار مصادر إضافية. وبالتالي فإن التعارض بين الوحي والعقل هو في حقيقته تعارض بين عقول، أو منهجيات متباينة في آليات استدلالها انطلاقاً من مصدري المعرفة الرئيسيين. ومن هنا تبرز الحاجة إلى الوعي المنهجي والنقد الأصولي في الدوائر العلمية.

ثالثاً: بما أن العلم يقوم على اليقين أو الظن الراجح لذلك يلزم اعتماد الأحكام الكلية وتغليبها على الأحكام الجزئية، سواء أصَدَرت الأولى عن نظر في نصوص الوحي أم عن معطيات الواقع. لذلك تنبه علماء الأصول منذ القديم إلى أن فعل الأمر في النصوص لا يفيد الوجوب، بل قد يقصد منه التخيير، كما في قوله

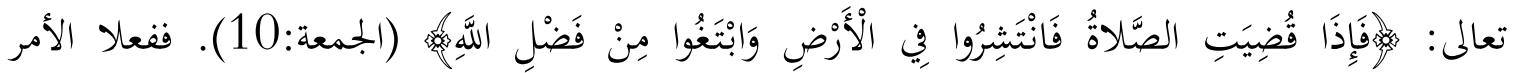
"انتشروا" و"ابتغوا" في الآية السابقة يفيدان الإباحة والتخيير لا الإيجاب والإلزام. ويعرف ذلك لكربك من خلال النظر في دلالات الحكم ضمن سياقه النصي والحالي. لذلك لاحظ الشافعي في رسالته أن تحديد الدلالة الخاصة أو العامة للنص لا يمكن أن تتم من خلال النظر في صيغة الألفاظ المركبة للعبارة القرآنية، بل تتطلب تحليل العبارة ومعارضتها بعبارة أخرى ضمن الخطاب القرآني. وبالتالي فإن دلالة النصوص القرآنية والنبوية المنفردة لا تفيد القطع بل الظن. بينما يتحصل اليقين عبر تضافر النصوص وتواطؤ المعاني والتوصل إلى أحكام كلية. كما لاحظ الشافعي في رسالته أن اللفظ العام قد يفيد الخصوص وقد يفيد اللفظ الخاص العموم. 52 وكذلك يمتنع عند دراسة الظواهر الكونية والنفسية التعميم من حالة واحدة، بل لا بد من تضافر الحالات وتواطئها لرجوح الظن.

$$
52 \text { 5ممد بن إدريس الشافعي: الرسالة، تحقيق أحمد محمد شاكر، بيروت: دار الكتب العلمية، د. ت، ص52-61. }
$$


رابعاً: نظراً لحاجة العقل إلى النظر في الجزئيات لتوليد معارف كلية، فإن العقل غير قادر على تكوين أحكام مضمونية في دائرة الوجود الغبي بالنظر المباشر، لانعدام المدركات الحسية المناسبة. لذلك فإن العقل محتاج إلى فهم نصوص الوحي لإدراك الطبيعة الكلية للوجود. لكن العقل قادر على إدراك صدور العالم عن إله عليم حكيم خبير قدير من خلال النظر في آيات الكون، بما أودع الله في من قدرات عقلية تربط السبب بالمسبب، وتعرف عظمة الصانع من عظيم صنعه. ولعل في قصة إبراهيم نبي الله عليه السلام عن مصدر الوجود مثالا لاستدلال العقل على مبدعِه:

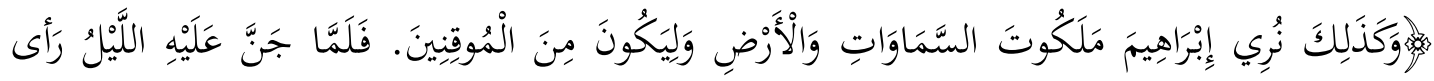

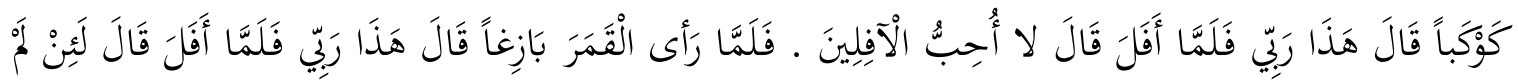

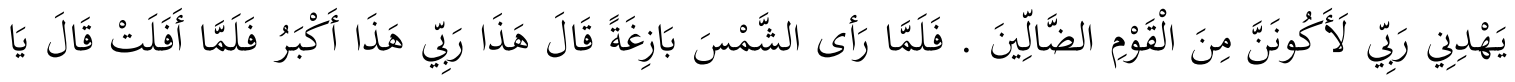

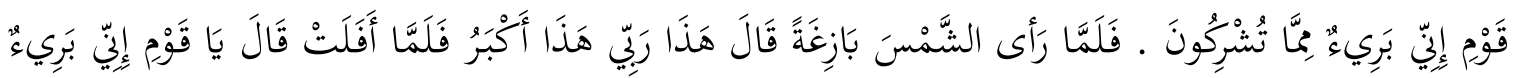

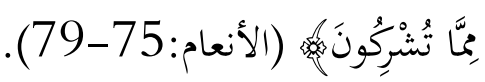

لقد أدرك إبراهيم بعقله الفطري أنه وما يهيط به صادر عن خالق قدير، واستطاع بالنظر في ملكوت الله الوصول إلى قناعة بأن الوجود كله من خلق الله العظيم. وكذلك فإن العقل البشري قادر على تبين صدق الوحي واستشعار علو الخطاب القرآي وعظمته، ونسبته إلى الله العلي القدير. لكن العقل محتاج بعد ذلك إلى اعتماد مضمون الوحي لتحديد بنية الوجود وغايته، ومعنى الحياة الإنسانية ومآلها.

خامساً: تشكل الأحكام الكلية المستمدة من الوحي المقدمات الوجودية والقيمية للنظريات المتعلقة بالظواهر الطبيعية والاجتماعية. ذلك أن النظر في الطبيعة والمجتمع يفترض قيام تصور عام عن بينة الوجود وغاية الخلق ومقاصد الاجتماع. فهذه معارف لا يمكن استخراجها بالملاحظة والتجربة، نظراً لارتباطها بالوجود الكلي للإنسان.

سادساً: يجب حمل نصوص الوحي المتعلقة بالظواهر الطبيعية والاجتماعية على معنى العموم لا الخصوص، وبالتالي يلزم فهمها بمقتضى المفاهيم والأحكام المستمدة من خلال تحليل الظواهر الطبيعية والاجتماعية، وبناءً على فهم قوانين حركتها. ذلك أن الغاية من الإشارات الطبيعية والتاريخية في الوحي تحفيز 
العقل للنظر والاعتبار، لا تشريح البنية الطبيعة أو تحليل الظواهر الاجتماعية. فالقرآن الكريم، كما يخبرنا المولى عز وجل، كتاب هداية. وبالتالي يتطلب الوصول إلى فهم دقيق لقوانين حركة الطبيعة والتاريخ الانكباب على دراسة تلك الظواهر من مصادرها. 